Revue des patrimoines

43 | 2021

Des écoles d'art académiques aux écoles d'art : des collections et des lieux, un patrimoine à valoriser

\title{
Un conservatoire des plâtres antiques, 1
}

Des Académies royales du XVII ${ }^{\mathrm{e}}$ siècle à la Nouvelle École royale et spéciale des beaux-arts (Paris) au XIX ${ }^{\mathrm{e}}$ siècle

A conservatory for plaster casts of ancient sculpture, 1. From the "Académies royales" of the $17^{\text {th }}$ century in Paris to the "Nouvelle École royale et spéciale des beaux-arts" (Paris) in the $19^{\text {th }}$ century

\section{Élisabeth Le Breton}

\section{(2) OpenEdition}

1 Journals

\section{Édition électronique}

URL : http://journals.openedition.org/insitu/28626

DOI : $10.4000 /$ insitu. 28626

ISSN : 1630-7305

Éditeur

Ministère de la Culture

\section{Référence électronique}

Élisabeth Le Breton, « Un conservatoire des plâtres antiques, 1 », In Situ [En ligne], 43 | 2021, document 4, mis en ligne le 12 janvier 2021, consulté le 14 janvier 2021. URL : http://journals.openedition.org/ insitu/28626 ; DOI : https://doi.org/10.4000/insitu.28626

Ce document a été généré automatiquement le 14 janvier 2021.

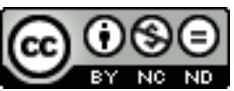

In Situ Revues des patrimoines est mis à disposition selon les termes de la licence Creative Commons Attribution - Pas d'Utilisation Commerciale - Pas de Modification 4.0 International. 


\section{Un conservatoire des plâtres antiques, 1}

Des Académies royales du XVII ${ }^{\mathrm{e}}$ siècle à la Nouvelle École royale et spéciale des beaux-arts (Paris) au XIX ${ }^{\mathrm{e}}$ siècle

A conservatory for plaster casts of ancient sculpture, 1. From the "Académies royales" of the $17^{\text {th }}$ century in Paris to the "Nouvelle École royale et spéciale des beaux-arts" (Paris) in the $19^{\text {th }}$ century

\section{Élisabeth Le Breton}

«Quels connaisseurs ce devaient être que ces Grecs! Quel tribunal pour l'artiste qu'un peuple

de gens de goût ! ${ }^{1}{ }^{\prime}$ (Eugène Delacroix.)

«Phidias obsède, décourage le médiocre et l'impuissant. Alors mort à ce gêneur, au modèle inaccessible! Aussi on peut voir, depuis quelques jours, sous la verrière, des tas de poudre blanche, des fragments de plâtre cassés, des membres disloqués. Ce sont des Vénus et des Apollons contestés [...]. Constestés à coups de marteau

$[\ldots]^{2}$.» (Pierre Mazars.)

1 Un siècle sépare ces deux citations. Devenu un des symboles même d'asservissement, le modèle idéal recommandé dans toutes les écoles du XVII ${ }^{\mathrm{e}}$ au $\mathrm{XIX}^{\mathrm{e}}$ siècle attire $\mathrm{au} \mathrm{XX}^{\mathrm{e}}$ les horions des iconoclastes.

2 Ainsi, dans les «temples » de la création artistique ou des réflexions théoriques sur l'art, depuis trois siècles utilisées par les enseignants et les artistes, des collections entières de tirages en plâtre ${ }^{3}$ sur l'antique s'écroulent sous les coups à partir de $1969^{4}$, déjà désacralisées. Ces plâtres étaient exposés comme modèles d'étude, d'inspiration et de réflexion, à l'École des beaux-arts de Paris, à la Sorbonne - Institut d'art et d'archéologie - ou au Louvre. 
Ce qu'il subsiste de ces ensembles, liés intrinsèquement pour une part importante au Louvre par dépôts ou dons, mais provenant pour une large part des deux autres institutions parisiennes précitées, est alors dépossédé de sa vocation initiale. Les plâtres quittent Paris ${ }^{5}$ et sont abrités sur le domaine de Versailles, non loin du parc du château, qui avait justifié la formation du noyau primordial conservé au palais du Louvre au XVII ${ }^{e}$ siècle. De cette désaffection, cette fois bien consommée, était née dès 1970 l'idée d'un «musée des Monuments antiques ${ }^{6}$ " érigé sous les voûtes de Jules Hardouin-Mansart. Il ne verra pas le jour. Il faut attendre 2001, quand est signé l'acte de naissance de ce qu'il est convenu d'appeler désormais la gypsothèque du musée du Louvre $^{7}$, dans la Petite Écurie du roi, pour voir renaitre un projet [fig. 1].

Figure 1

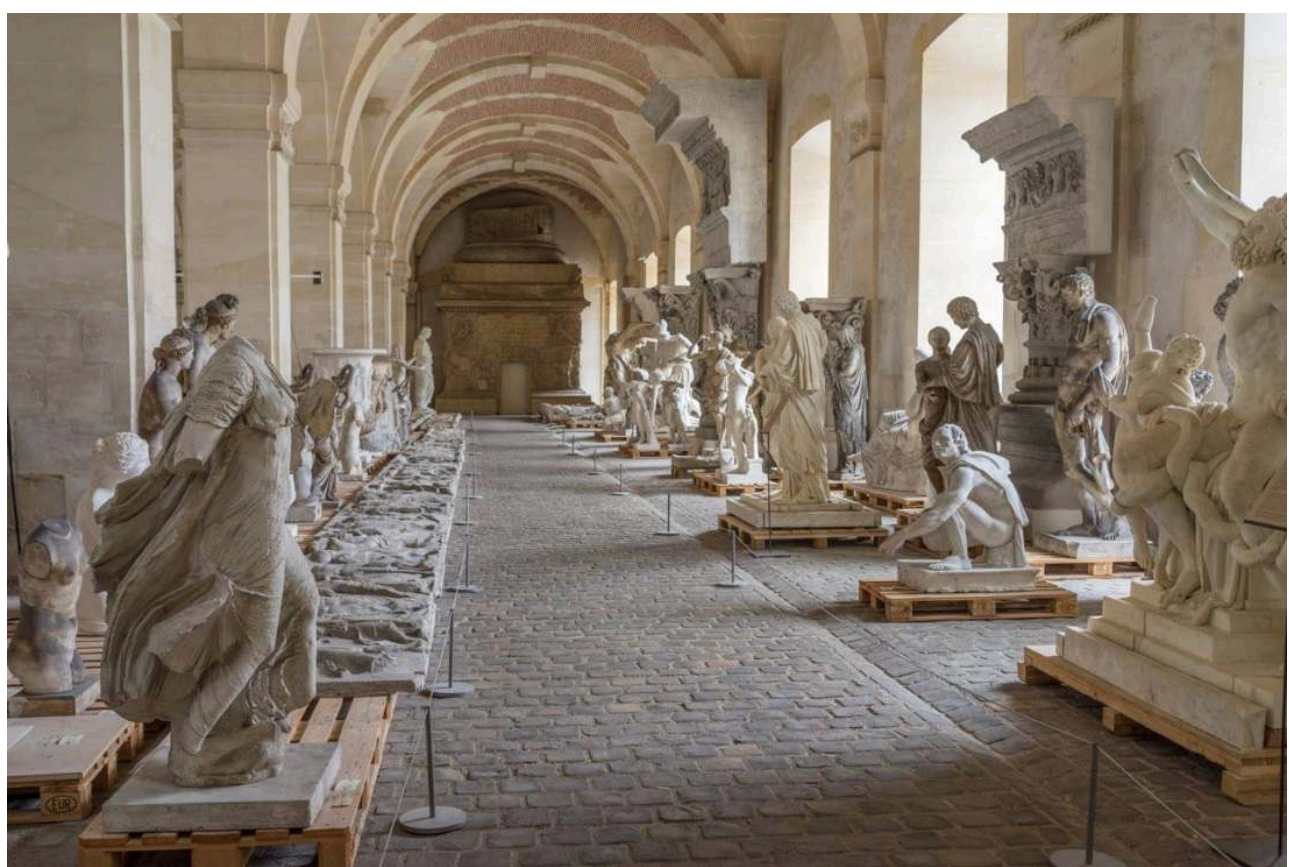

Au fond de la galerie romaine de la gypsothèque du musée du Louvre, on peut voir la base de la colonne Trajane reconstituée : le plus célèbre des monuments de l'Antiquité, qui commémore à Rome la victoire de Trajan sur les Daces.

Colonne Trajane, tirage en plâtre (moule à bon creux et à pièces) conservé à la gypsothèque du musée du Louvre (Gy 1520), Petite Écurie du roi à Versailles (œuvre originale conservée in situ au Forum de Rome, Italie).

(c) Photo Hervé Lewandowski (RMN-Grand Palais).

Le fonds de cette collection est riche de plus de 5000 tirages historiques $^{8}$ dont les modèles sont bien connus, exclusivement empruntés aux grandes références de l'Antiquité gréco-romaine (statues, bas-reliefs ou éléments d'architecture). Le répertoire est vaste et porte en lui toute la réception de l'antique en Europe et spécialement en France, du $\mathrm{XvII}^{\mathrm{e} 9}$ au $\mathrm{Xx}^{\mathrm{e}}$ siècle, transformant le lieu en un véritable conservatoire. Mais dans quel passé s'enracine-t-il?

5 Les travaux de restauration et de recherche accomplis par le musée du Louvre depuis 2001 permettent aujourd'hui d'éclairer quelques pans de cette histoire et d'en brosser un panorama. Mais la mémoire de cet ensemble ne peut être entièrement « restaurée » qu'avec une vigilance constante. Fruit d'un processus de duplication, le moulage, reproduit souvent par plusieurs opérations au cours de l'histoire, dans un matériau non 
datable, le plâtre, chaque tirage, jamais signé, exceptionnellement daté présente un pedigree difficile à déterminer.

\section{De l'art de copier en plâtre}

6 L'art de mouler en plâtre se développe dès l'Antiquité mais acquiert une réalité particulière à l'époque romaine, pendant la période classique. En effet, après avoir vidé la Grèce et ses sanctuaires de toute œuvre d'art, dans les valeurs éthiques comme dans les arts de Rome, l'idéal à atteindre est alors grec. L'un des moyens les plus sûrs et les moins onéreux pour étancher la soif d'une aristocratie romaine qui aspire à atteindre parfaitement cet idéal fut de constituer des répertoires de modèles en plâtre, afin de permettre aux artistes d'honorer cette forme de culte qu'ils allaient développer à grande échelle. Le site archéologique de Baïes ${ }^{10}$, (aujourd'hui Baia), au nord du golfe de Naples, a ainsi livré les premiers « recueils » connus, largement «feuilletés » par les sculpteurs et traduits en marbre - soit des copies romaines d'originaux grecs exécutées à partir de tirages en plâtre. Quelques-uns de ces modèles très prisés et reconnus à Baïes se trouvent encore dans la gypsothèque du musée du Louvre. C'est le cas, par exemple, des statues d'Aristogiton [fig. 2] ou de l'Amazone Mattei, dont le succès, pour cette dernière, ne s'est jamais démenti.

Figure 2

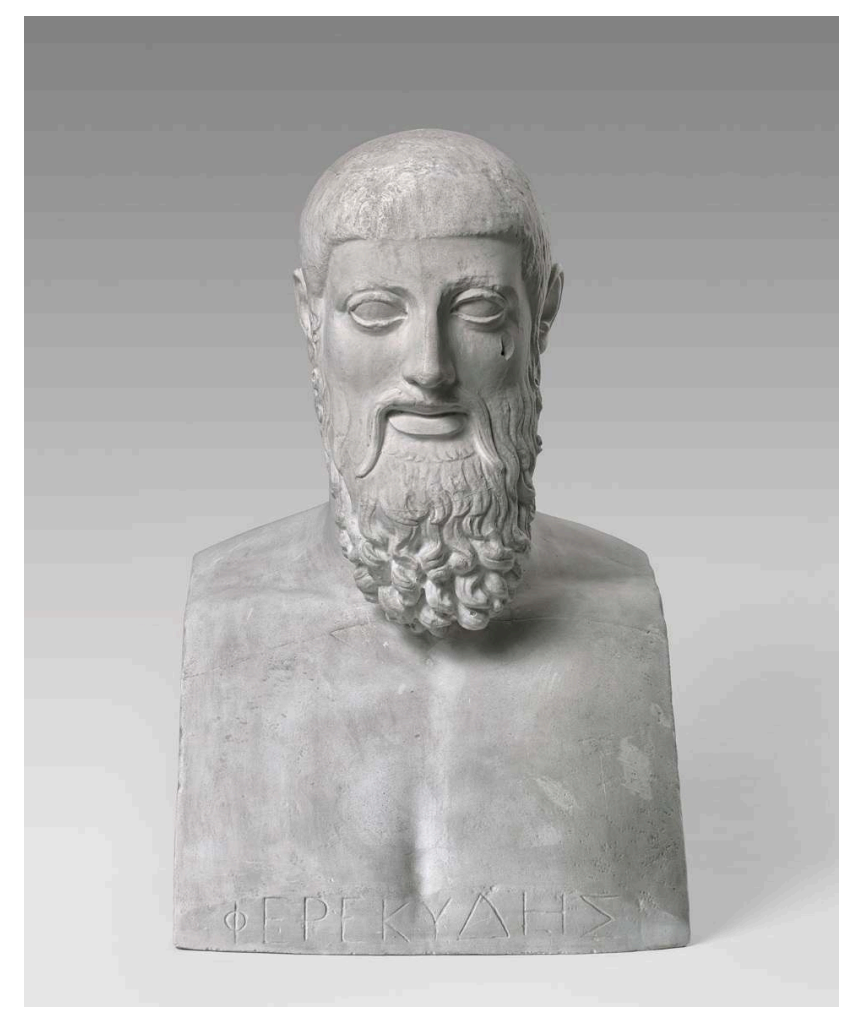

Aristogiton, $x x^{\mathrm{e}}$ siècle, tirage intégral en plâtre (moule à bon creux et à pièces) (h. $50 \times 1.33,5 \mathrm{~cm}$ ) conservé à la gypsothèque du musée du Louvre (Gy 0396), Petite Écurie du Roi à Versailles (œuvre originale conservée au Musée archéologique national à Madrid, Espagne).

(c) Photo Hervé Lewandowski (RMN-Grand Palais) 


\section{De Rome copieur à Rome copié}

7 Cette fascination exercée par le monde grec sur la culture romaine trouve un écho à partir $\mathrm{du} \mathrm{Xv}^{\mathrm{e}}$ siècle mais plus encore au siècle suivant, quand Rome commence à exhumer son passé sculpté ${ }^{11}$. En effet, les vastes travaux urbains dans la Rome du $\mathrm{XVI}^{\mathrm{e}}$ siècle permettent la découverte d'œuvres d'art - précisément des copies en marbre d'antiques grecs (souvent en bronze) du début de l'ère chrétienne - que l'Europe entière, qui, déjà, avait assimilé les valeurs morales et politiques prônées dans l'Empire, convoite d'emblée et avec constance.

8 La législation des États pontificaux n'autorise toutefois pas la sortie de leur territoire des œuvres d'art. Aussi, pour satisfaire à son tour cette soif d'antique et ce qu'elle véhicule, après obtention d'une autorisation spéciale, le moulage devient la technique d'appropriation d'un modèle, et le plâtre, le matériau de choix.

En précurseur, François $\mathrm{I}^{\mathrm{er}}$ aborde alors le tournant décisif qui allait inscrire cet idéal romain, et plus tard grec, comme le modèle absolu à graver sur les plus hauts frontons des académies, des musées et des universités. Ainsi, Fontainebleau, en premier lieu, s'enorgueillit « des plus belles statues antiques récemment découvertes ${ }^{12}$ " qui furent tirées en bronze en France à partir de creux rapportés d'Italie par Le Primatice en 1540. Cependant, hormis une grande partie des fontes elles-mêmes, rien ne subsiste de cette première campagne de moulage. Les matrices ont été vendues ${ }^{13}$. Nous avons cependant un témoin en plâtre, bien daté, issu d'un moule du $\mathrm{XvI}^{\mathrm{e}}$ siècle. Il provient de la campagne de prise d'empreinte des marbres du groupe des Niobides acquis en 1583 par le cardinal Ferdinand de Médicis pour orner sa villa romaine. Ces plâtres ont été réalisés à la demande du cardinal, en 1587, quand, juste nommé grand-duc de Toscane, il s'apprêtait à s'installer à Florence. Seulement, la collection médicéenne riche d'un grand nombre de marbres antiques que l'on venait de redécouvrir, était déjà célèbre à travers l'Europe, et l'on se pressait dans la Ville éternelle pour contempler ces œuvres qui faisaient la renommée des Médicis. Ferdinand commande alors un jeu en plâtre qui lui est livré à Florence en 1588. Deux jeux semblent avoir été exécutés et un Niobide couché, encore dit Niobide mort, a été retrouvé dans la collection de la gypsothèque du Louvre, dans son état au moment de sa découverte, lacunaire ${ }^{14}$ [fig. 3]. 


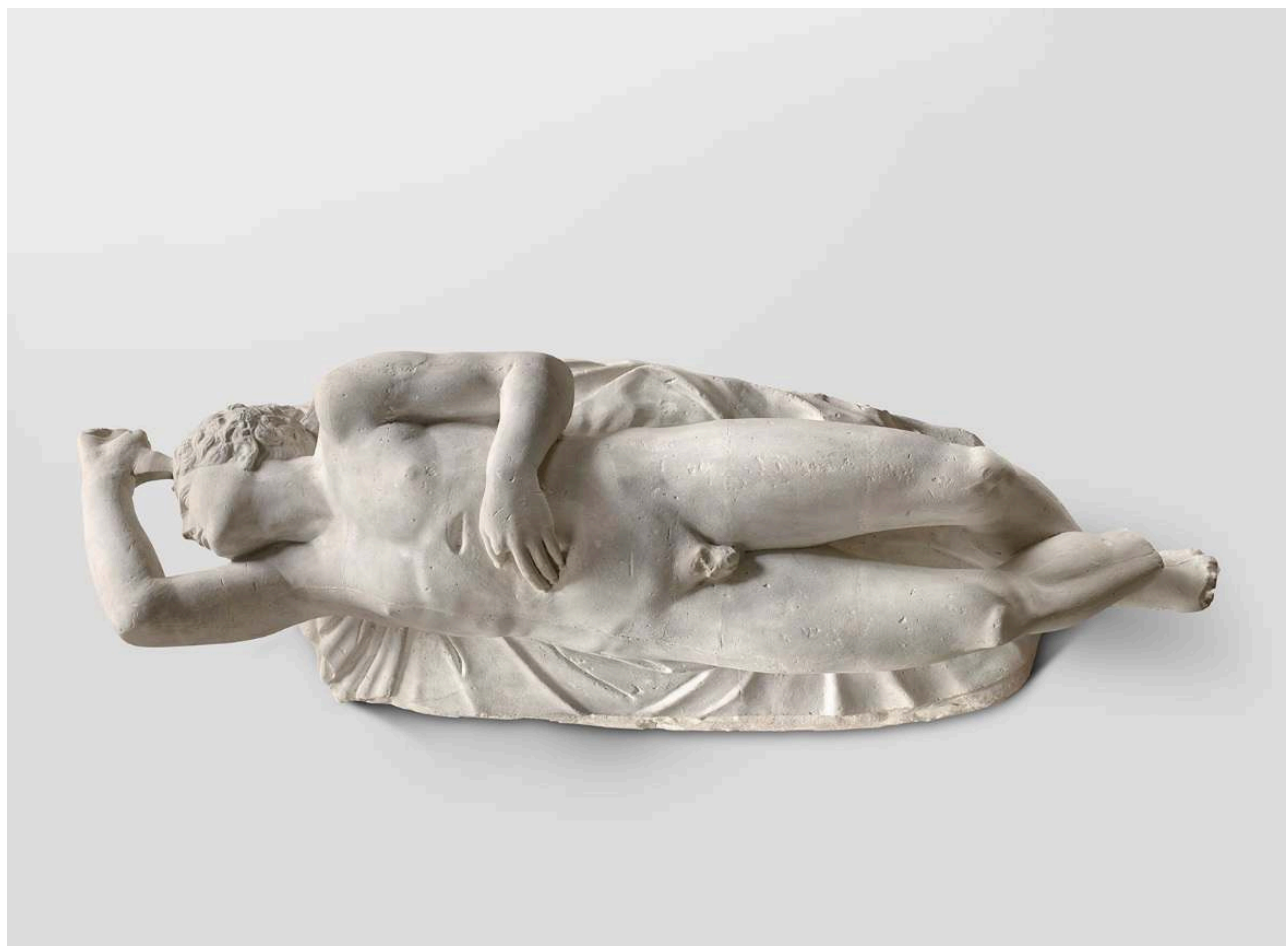

Niobide couché, sculpté entre 1583 et 1587, tirage intégral en plâtre (moule à bon creux et à pièces) (h. 48 x I. $157 \mathrm{~cm}$ ) conservé à la gypsothèque du musée du Louvre (Gy 0228), Petite Écurie du roi à Versailles (œuvre originale conservée à la Galerie des Offices, Florence, Italie)

(c) Photo Hervé Lewandowski (RMN-Grand Palais).

10 Malgré tout, et même si ce n'est qu'au siècle suivant qu'une véritable impulsion est donnée, cette entreprise bellifontaine, alors que très peu d'antiques circulent, constitue bien le socle sur lequel repose désormais l'Antiquité accessible et visible en France.

11 La majorité des références choisies à cette époque, toutes illustres, constitue dès lors un répertoire de formes, et est encore bien présente dans la gypsothèque du Louvre. Les modèles de statues comme le Laocoon, la Cléopâtre, l'Apollon, la Vénus, le Commode, le Nil et les plaques de la colonne (sous-entendu "Trajane») sont en effet restés très appréciés du pouvoir et des artistes au cours des siècles suivants, et jusqu'à nos jours. Il suffit de constater la place réservée à ces « icônes » dans l'œuvre de l'artiste Jeff Koons pour s'en convaincre ${ }^{15}$.

Les prises d'empreinte de ces modèles ont bien sûr été renouvelées depuis le Xvi siècle, au XVII ${ }^{\mathrm{e}}$ siècle puis régulièrement ensuite, à Rome encore souvent mais parfois aussi à Paris, à partir de tirages précédents. Certains des bronzes de Fontainebleau ont euxmêmes pu servir de modèles. Mais il est parfois bien délicat de repérer la matrice d'origine et le circuit de diffusion. L'Ariane endormie, objet de prédilection dès le $\mathrm{XVI}^{\mathrm{e}}$ siècle, était encore moulée aux $\mathrm{XVII}^{\mathrm{e}}, \mathrm{XIX}^{\mathrm{e}}$ et $\mathrm{XXI}^{\mathrm{e}}$ siècles. L'exemplaire de la gypsothèque, issu des collections de l'École des beaux-arts, fut moulé précisément à Rome puis tiré dans la première moitié du XIX ${ }^{\mathrm{e}}$ siècle $^{16}$ [fig. 4]. 


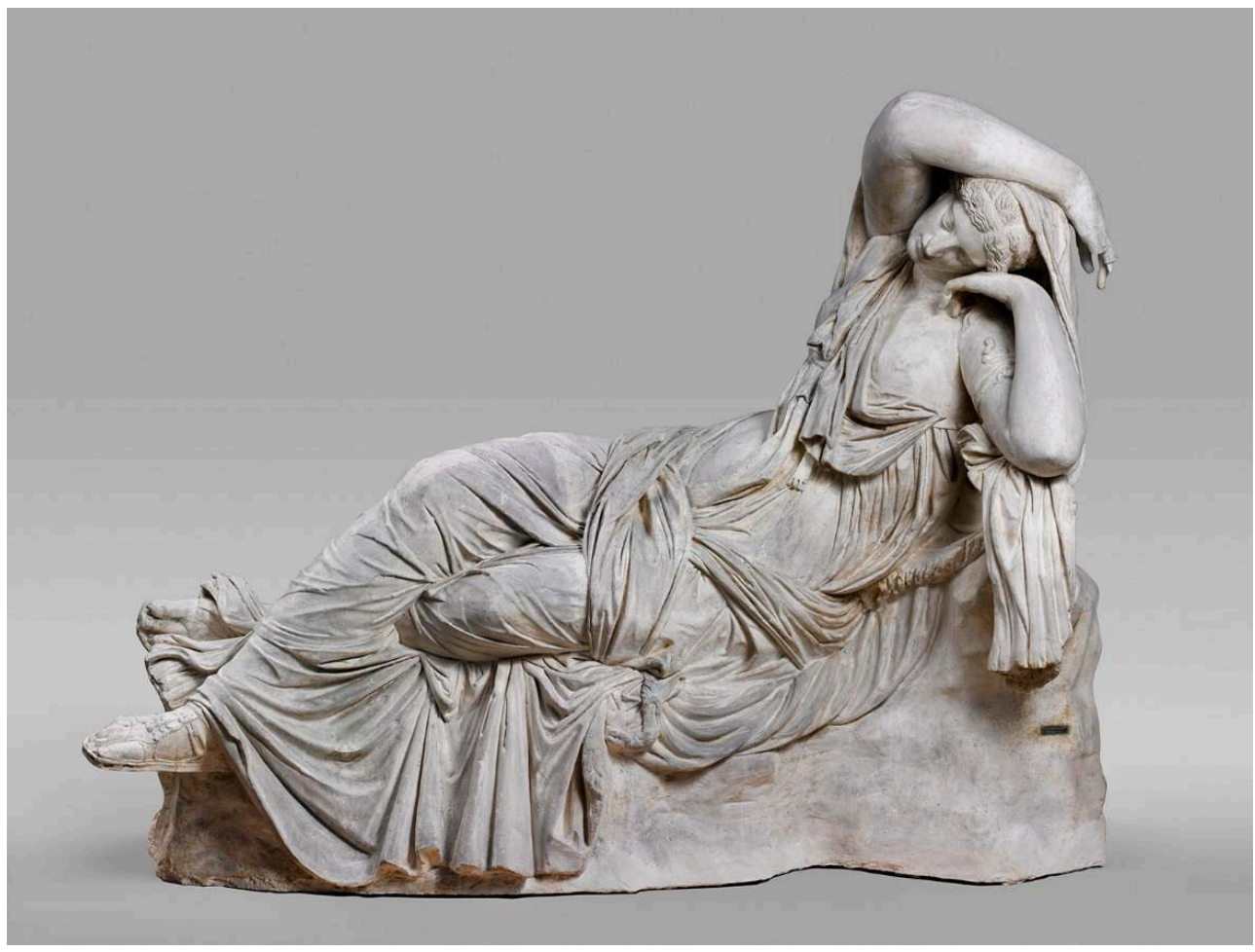

Ariane endormie, autrement nommée Cléopâtre, 1850, tirage intégral en plâtre par Leopoldo Malpieri (moule à bon creux et à pièces) (h. $162 \times 1.241$ x p. $84 \mathrm{~cm}$ ) conservé à la gypsothèque du musée du Louvre (Gy 0963), Petite Écurie du roi à Versailles (œuvre originale conservée au musée PioClémentino, Vatican).

(C) Photo Hervé Lewandowski (RMN-Grand Palais).

Mais le modèle de l'Hercule Farnèse utilisé par les Ateliers d'art de la Réunion des musées nationaux - Grand-Palais pour réaliser en France l'Hercule des Gazing Balls de Jeff Koons en 2013 révèle une circulation complexe. Son « original » est un plâtre qui appartient aux Musées royaux de Bruxelles. Un moulage sur un tirage est généralement pratiqué quand le modèle original n'est pas accessible ou est trop endommagé. Il s'agit ici d'un plâtre du XIX ${ }^{e}$ siècle qui a permis un surmoulage ${ }^{17}$, suivi d'un surtirage, réalisé à partir d'un matériau singulier élaboré par le Studio Koons, un plâtre de synthèse nommé «ultra blanc».

\section{Pour une Rome à Paris}

C'est au moment où les collections royales commencent à s'étoffer, sous Louis XIV, que naît peu à peu l'idée d'un possible corpus à placer sous les yeux des artistes. En effet, en 1648 , alors qu'il s'agit de "relever les arts par une savante direction et de grands exemples $^{18}$ ", Paris initie le mouvement. Mazarin, à l'instigation de Charles Le Brun, fonde au Louvre l'Académie royale de peinture et de sculpture, complétée par l'École académique, où des leçons sur les œuvres sont dispensées aux artistes. Active de manière effective à partir des années 1660 , cette Académie profite de l'arrivée à partir de 1666 de modèles romains en plâtre, qui vont constituer le premier noyau du répertoire. La même année, Colbert encourage ce mouvement en créant l'Académie de 
France à Rome, qui devient alors le grand centre de formation des artistes que l'on connaît, épicentre de la diffusion des modèles [fig. 5-10].

\section{Figure 5}

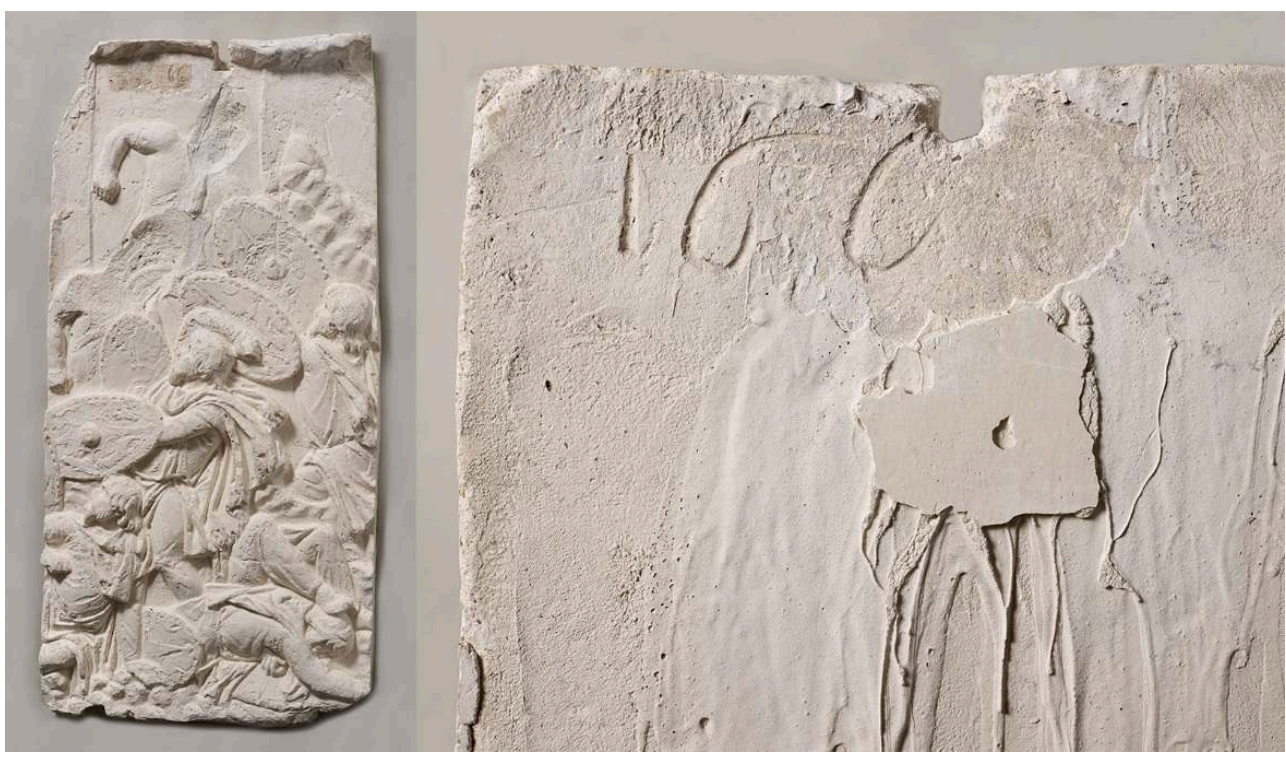

Plaque de la frise de la colonne Trajane (vue d'ensemble à gauche, vue de détail à droite), tirage partiel en plâtre réalisé en 1669 (moule à bon creux et à pièces) $(\mathrm{h} .116 \times \mathrm{I} .58 \mathrm{~cm})$ conservé à la gypsothèque du musée du Louvre (Gy 1520), Petite Écurie du roi à Versailles (œuvre originale conservée in situ au Forum de Rome, Italie).

En 1545 déjà, François Ier confie au Primatice la mission de jeter en plâtre quelques plaques des parties basses de la colonne Trajane pour Fontainebleau. En 1665, avant même la création de I'Académie de France à Rome, Louis XIV fait mouler l'ensemble de la colonne. Cette plaque retrouvée récemment dans la gypsothèque du Louvre témoigne de cette campagne menée au xvı siècle : au recto, la date « 1669 », à présent partiellement effacée, a été inscrite à l'encre, tandis qu'au verso l'inscription gravée « 166 » demeure nettement visible.

(c) Photos Anne Chauvet (RMN-Grand Palais). 
Figure 6

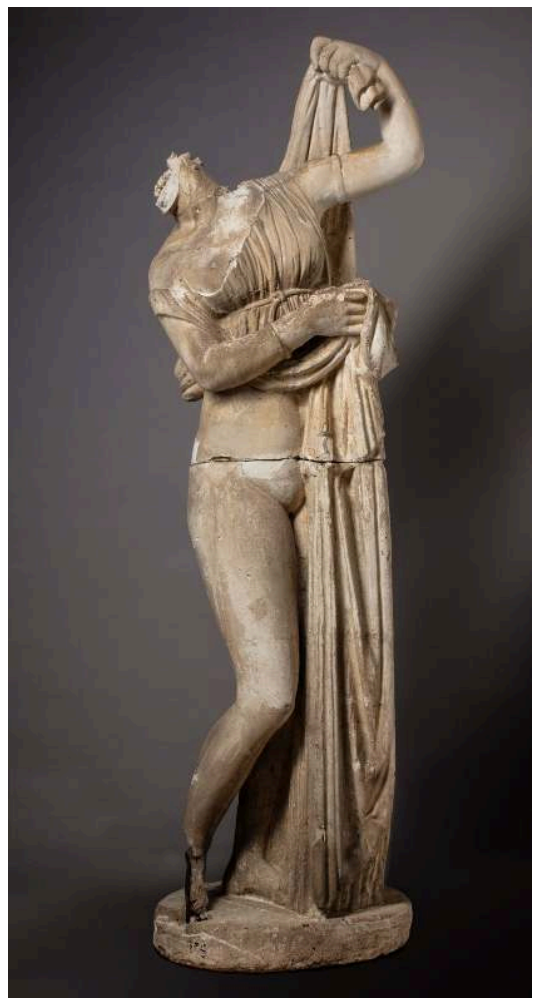

Vénus callipyge, autrement nommée, en particulier sous l'Ancien régime, La Vénus aux belles fesses, tirage intégral en plâtre réalisé entre 1666 et 1673 (moule à bon creux et à pièces) (h. $168 \times 1.50$ x p. $40 \mathrm{~cm}$ ) conservé à l'Académie de France à Rome (inv. 2015.0.203) (œuvre originale conservée au Musée archéologique de Naples, Italie).

(c) Giuseppe Schiavinotto (Académie de France à Rome - Villa Médicis, 2019). 
Figure 7

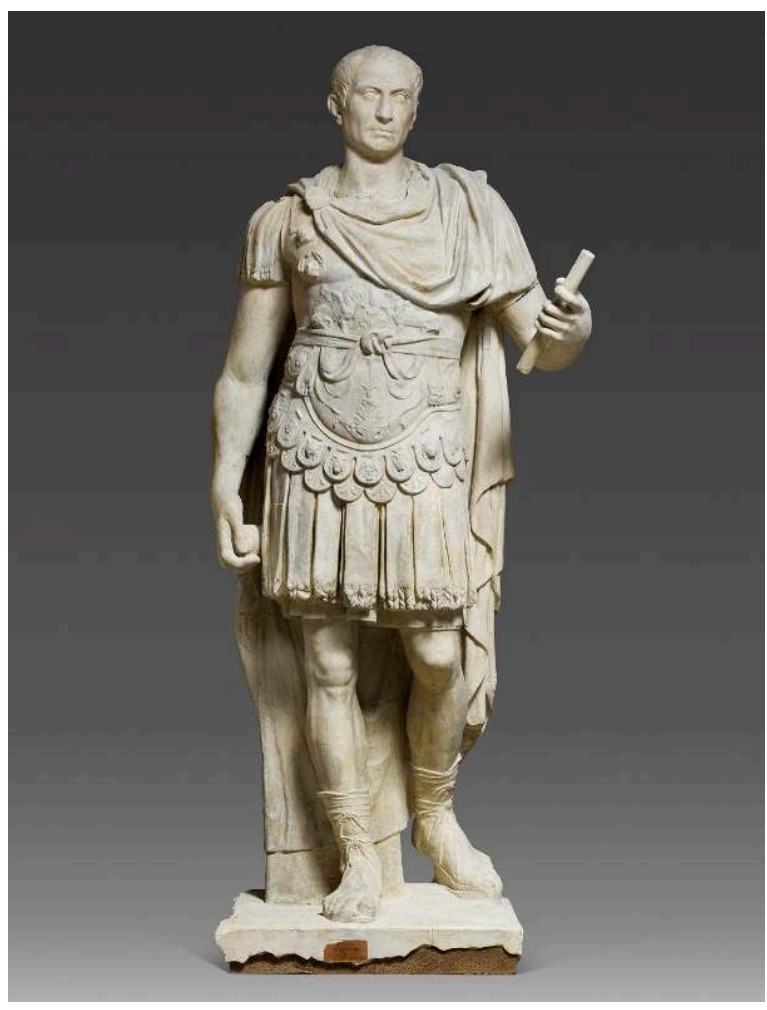

Une statue dite César après sa restauration, tirage intégral en plâtre réalisé par Giovanni Arnaldi en 1685 (moule à bon creux et à pièces) (h. 294 x I. 119 x p. 79 cm) conservé à la gypsothèque du musée du Louvre (Gy 0199), Petite Écurie du roi à Versailles (œuvre originale conservée au palais des Conservateurs, musées du Capitole à Rome, Italie).

(c) Photo Hervé Lewandowski (RMN-Grand Palais). 
Figure 8

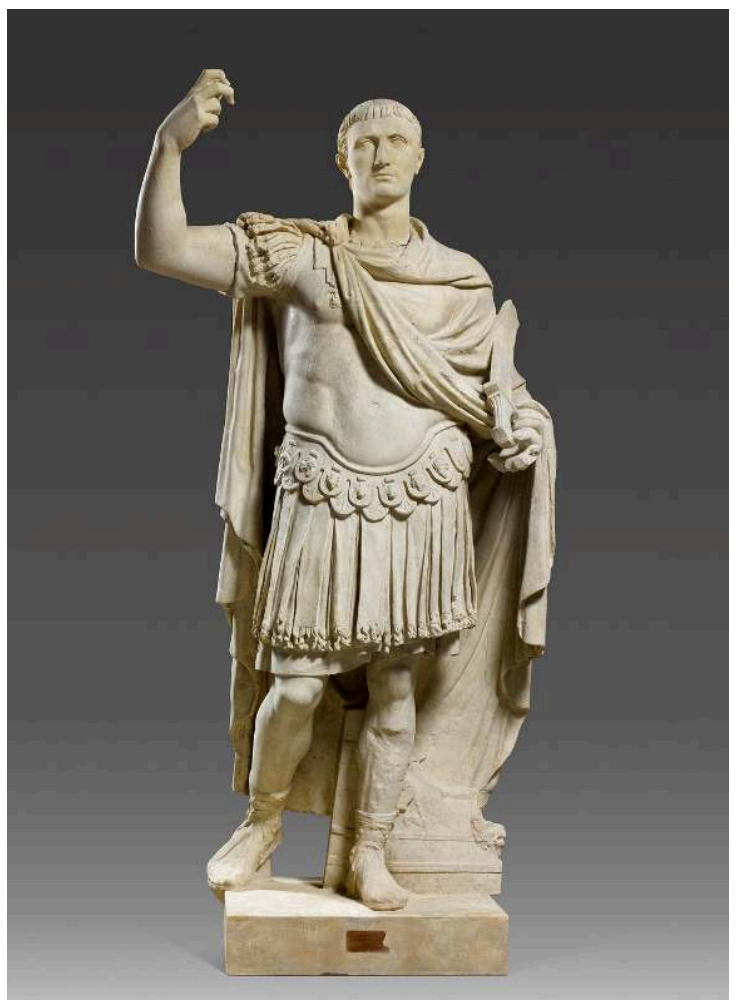

Une statue dite Auguste après sa restauration, tirage intégral en plâtre réalisé par Giovanni Arnaldi en 1685 (moule à bon creux et à pièces) (h. 286 x l. 140 x p. 95 cm) conservé à la gypsothèque du musée du Louvre (Gy 0198), Petite Écurie du roi à Versailles (œuvre originale conservée au palais des Conservateurs, musées du Capitole à Rome, Italie).

(c) Photo Hervé Lewandowski (RMN-Grand Palais). 


\section{Figure 9}

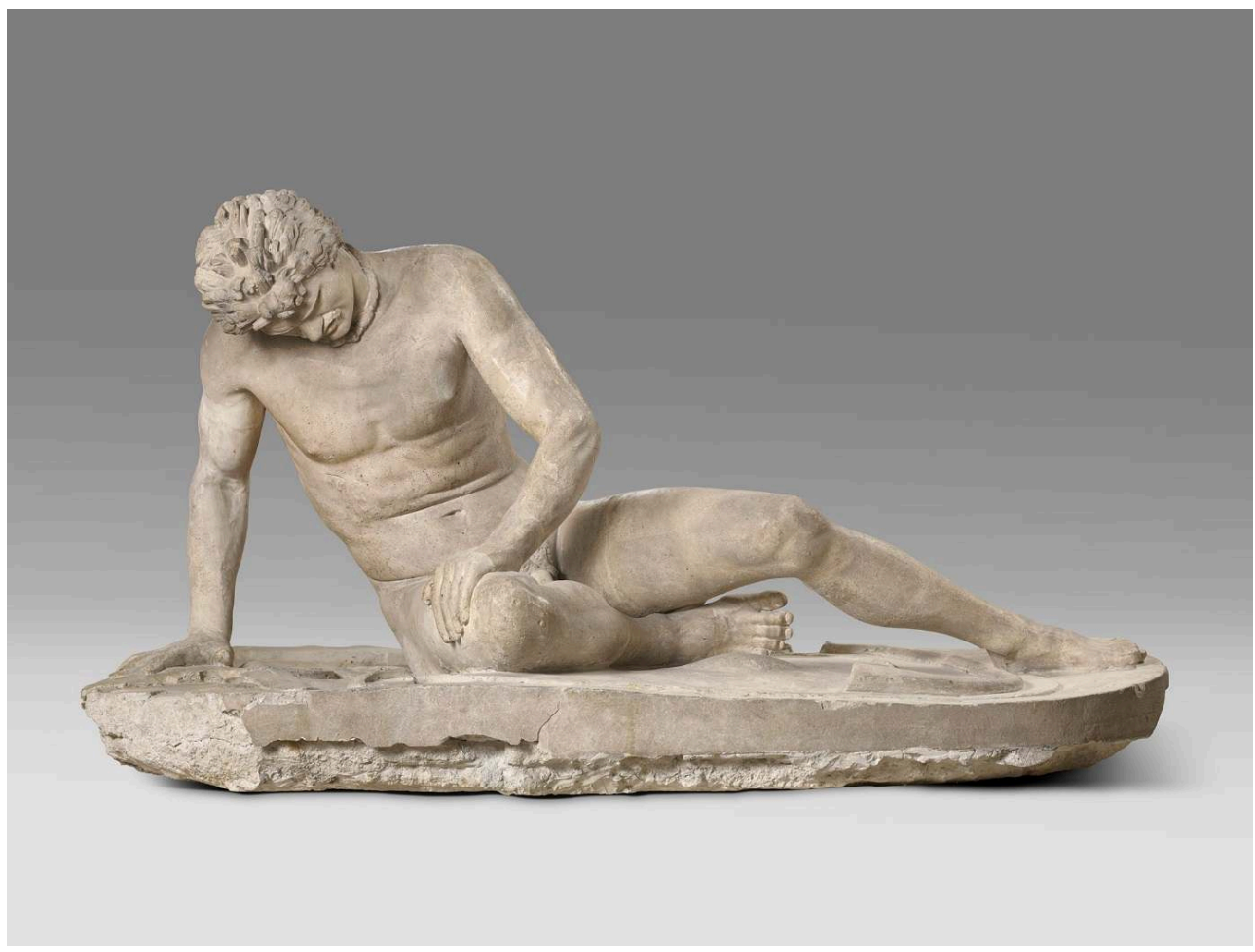

Le Gaulois mourant, autrement nommé Le Gladiateur mourant ou Mirmilon, tirage intégral en plâtre réalisé entre 1673 et 1684 (moule à bon creux et à pièces) (h. 100 x I. 190 cm) conservé à la gypsothèque du musée du Louvre (Gy 0249), Petite Écurie du roi à Versailles (œuvre originale conservée au palais des Conservateurs, musées du Capitole à Rome, Italie).

(c) Photo Hervé Lewandowski (RMN-Grand Palais). 


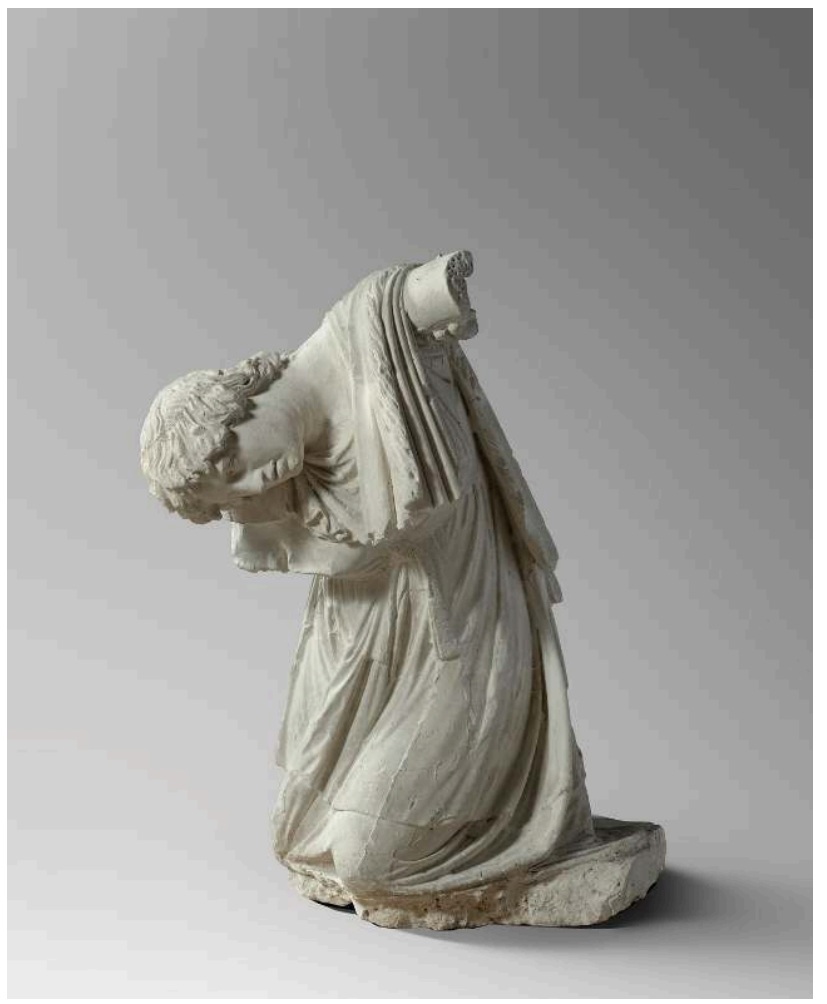

Gauloise mourante du groupe Ludovisi, autrement nommée Gaulois et sa femme, Arria et Paetus ou Pyrame et Thisbé, tirage intégral en plâtre réalisé entre 1673 et 1684 (moule à bon creux et à pièces) (h. 124 x I. $91 \mathrm{~cm}$ ) conservé à la gypsothèque du musée du Louvre (Gy 0904), Petite Écurie du roi à Versailles (œuvre originale conservée au Musée national romain, palais Altemps, Rome, Italie, inv. 114).

(c) Photo Hervé Lewandowski (RMN-Grand Palais).

15 Grâce à cela, dans cette seconde moitié du XviI siècle et dans ces cadres officiels, un véritable corpus romain est élaboré à Paris. Le premier moulage offert par le roi à l'Académie royale, le 27 février 1666, est l'« Hercule dit Pharnaise » [fig. 11]. D'autres suivront régulièrement: en 1682,14 pièces, puis encore, en mars 1692, en novembre 1693 et le 26 avril 1710, soit à cette date, 34 pièces $^{19}$ de modèles antiques [fig. 1]. Simultanément, en 1671, est créée l'Académie royale d'architecture, qui rejoint les salles du Louvre en 1692 et est dotée d'une école à partir de 1694. Ces Académies, riches d'un ensemble de modèles à imiter puis à surpasser, jouèrent un rôle fondamental dans les commandes de Versailles ${ }^{20}$. 
Figure 11

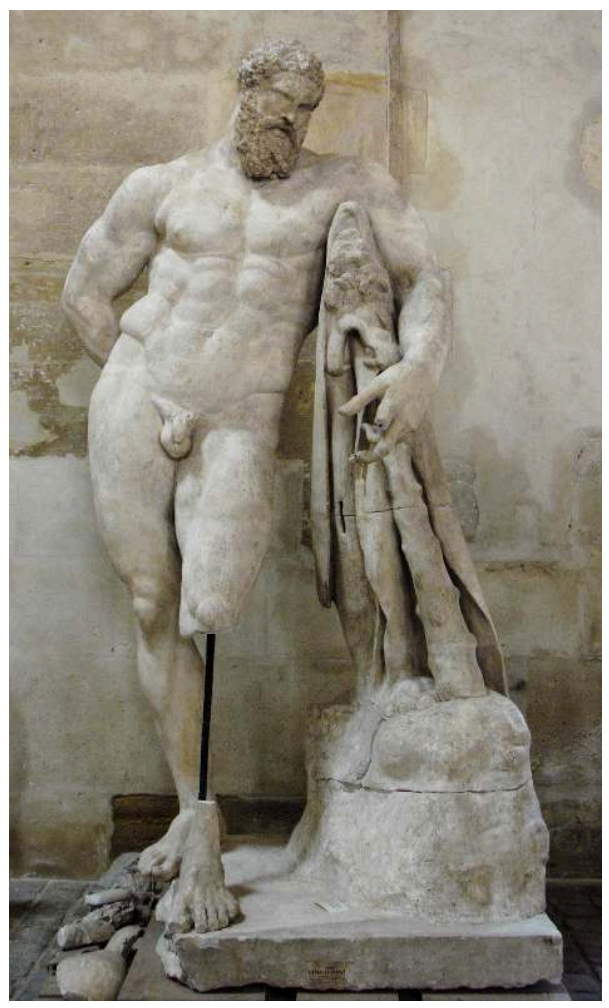

Hercule Farnèse, surmoulage (moulage d'un tirage en plâtre réalisé au moyen d'un moule à bon creux et à pièces) intégral en plâtre exécuté en 1666-1667 par un atelier parisien (h. 326 x I. 160 x p. 112 cm) conservé à la gypsothèque du musée du Louvre (Gy 1300), Petite Écurie du roi à Versailles (œuvre originale conservée au Musée archéologique de Naples, Italie).

(c) Photo Musée du Louvre / AGER, Service d'étude et de documentation.

Mais hors Académie, les collections royales proprement dites, abritées en voisines au Louvre, sont pour la première fois, à notre connaissance, enregistrées. André Félibien (1619-1695), historiographe du roi à partir de 1666 et secrétaire de l'Académie d'architecture mais surtout garde des Antiques, rédige un premier inventaire ${ }^{21}$ en 1692 [fig. 12]. Des listes de pièces (parties constituant les moules) et d'œuvres, conservées dans la "Sale des Suisses », sont ainsi enregistrées avec la particularité, quelque peu surprenante pour nous, de s'ouvrir par la collection royale des "Creux, ou Moules », suivie immédiatement de la liste des "Plastres", [fig. 13-16] avant de se terminer par celle des marbres. La priorité donnée aux creux et leur conservation au palais révèlent la place qui leur est accordée dès cette époque. Obtenir une autorisation pour une prise d'empreinte reste en effet un privilège rarement accordé, auquel s'ajoutent les difficultés techniques liées à l'art de "jeter ${ }^{22}$ " et le coût important d'une telle opération. Ainsi, les moules, objets de grand prix, ne sortent pas des murs du palais. Cette disposition demeurera par la suite ${ }^{23}$. En effet, quand l'atelier de moulage est créé à la fin du XviII ${ }^{e}$ siècle, installé dans l'enceinte du Louvre, il cohabite avec les salles d'exposition ${ }^{24}$; les moules et les modèles sont placés sous protection ${ }^{25} \mathrm{du}$ Garde des Antiques et les mouleurs eux-mêmes sont très surveillés, de façon à garantir l'inaliénabilité des pièces. Cette conservation des creux offre par ailleurs un éclairage qui contredit l'idée assez communément admise selon laquelle, dans ces temps anciens, ils ne pouvaient être fabriqués qu'en terre et ne servir qu'une seule fois. La vente des creux de Fontainebleau témoignait déjà du contraire au xvi ${ }^{e}$ siècle, et nous avons 
découvert dans les collections de l'Académie de France à Rome un moulage parfaitement identique au tirage d'une statue de Commode en Hercule de la gypsothèque du Louvre. Tous les deux sont sortis d'un même moule du XvII siècle, ce qui est un cas unique [fig. 17, fig. 18].

Figure 12

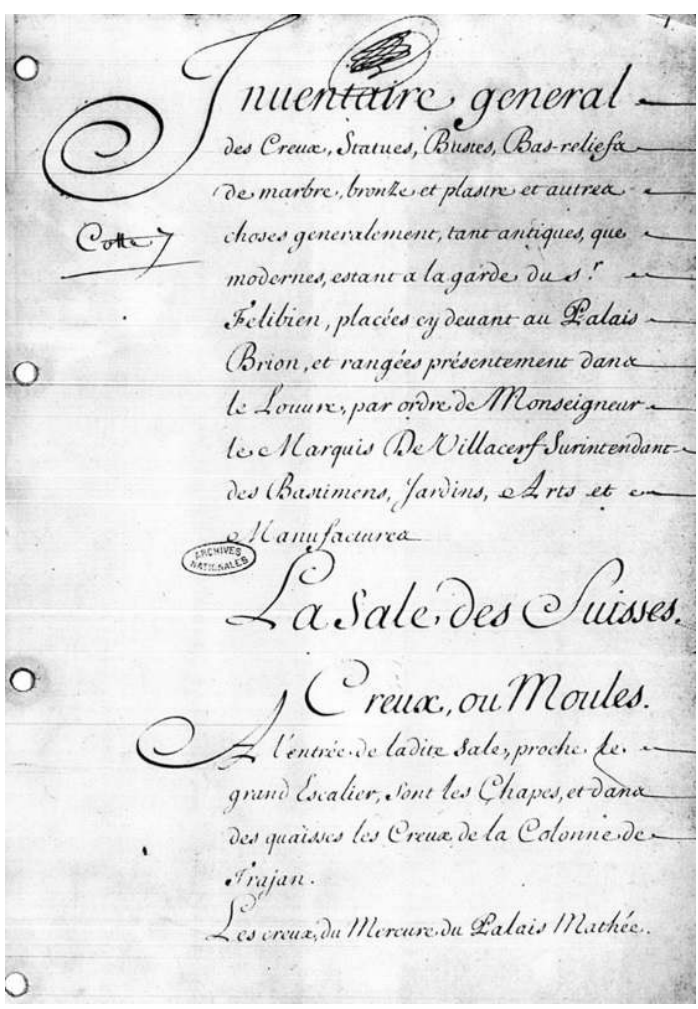

Première page de l'Inventaire général des œuvres des collections royales, 1692, conservé aux Archives nationales (sous-série O ${ }^{1}$ Maison du roi, cote 0 ${ }^{1 *} 1977^{A}$ ).

(c) Musée du Louvre / AGER, Service d'étude et de documentation. 


\section{Figure 13}

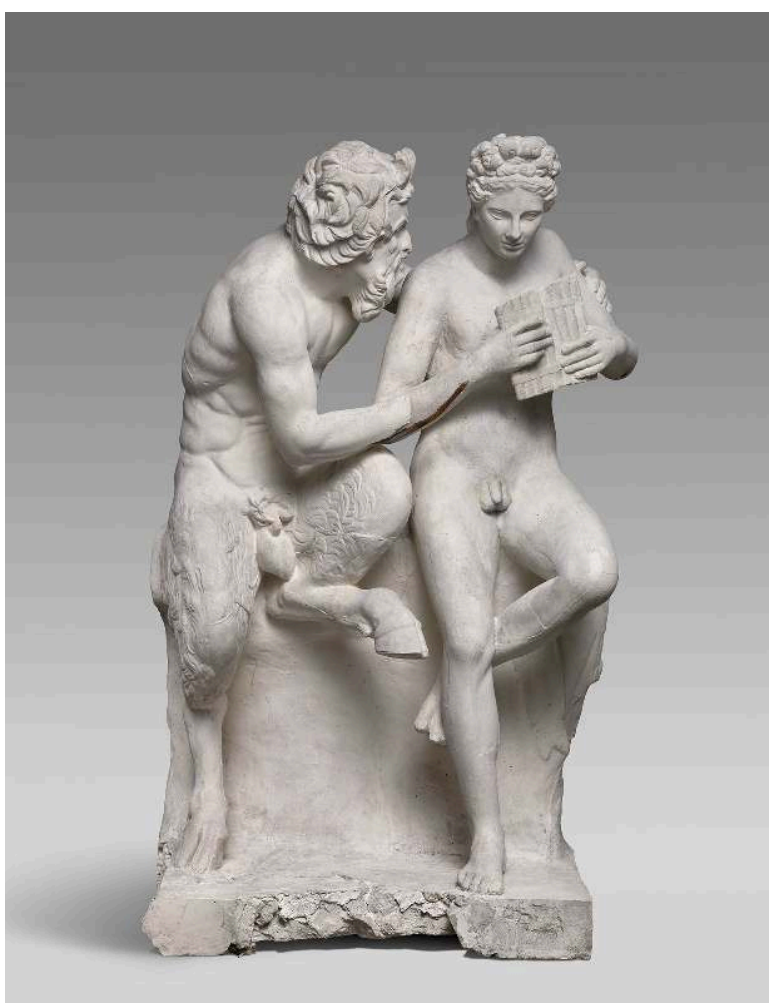

Pan et Olympe autrement nommé Pan et Apollon, Pan et Daphnis, Marsyas et Olympos, mais encore Satyre et un enfant, tirage intégral en plâtre (moule à bon creux et à pièces) réalisé en 1684 (h. $148 x$ $1.89 \mathrm{~cm}$ ) conservé à la gypsothèque du musée du Louvre (Gy 0187), Petite Écurie du roi à Versailles (œuvre originale conservée au musée des Offices, Florence, Italie).

(c) Photo Hervé Lewandowski (RMN-Grand Palais). 
Figure 14

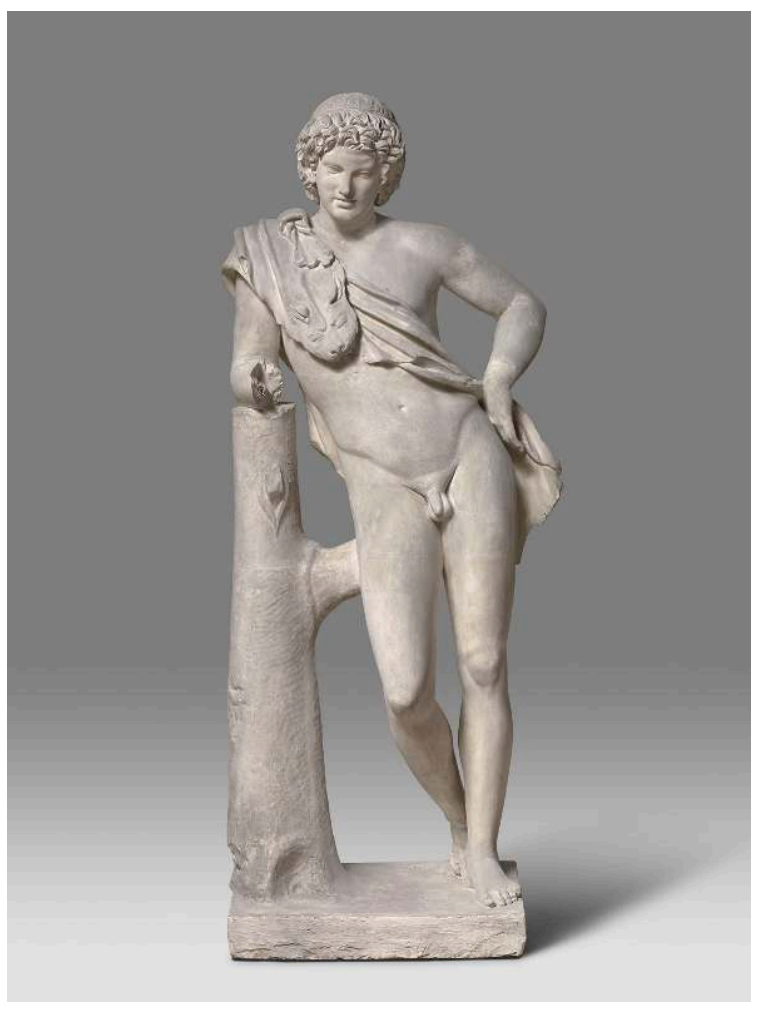

Faune du Capitole autrement nommé Satyre au repos ou Faune de Praxitèle, tirage intégral en plâtre (moule à bon creux et à pièces) réalisé au xIx siècle $(\mathrm{h} .183 \times \mathrm{I} .72 \mathrm{~cm})$ conservé à la gypsothèque du musée du Louvre (Gy 0609), Petite Écurie du roi à Versailles (œuvre originale conservée au musée du Capitole, Rome, Italie).

(c) Photo Hervé Lewandowski (RMN-Grand Palais). 
Figure 15

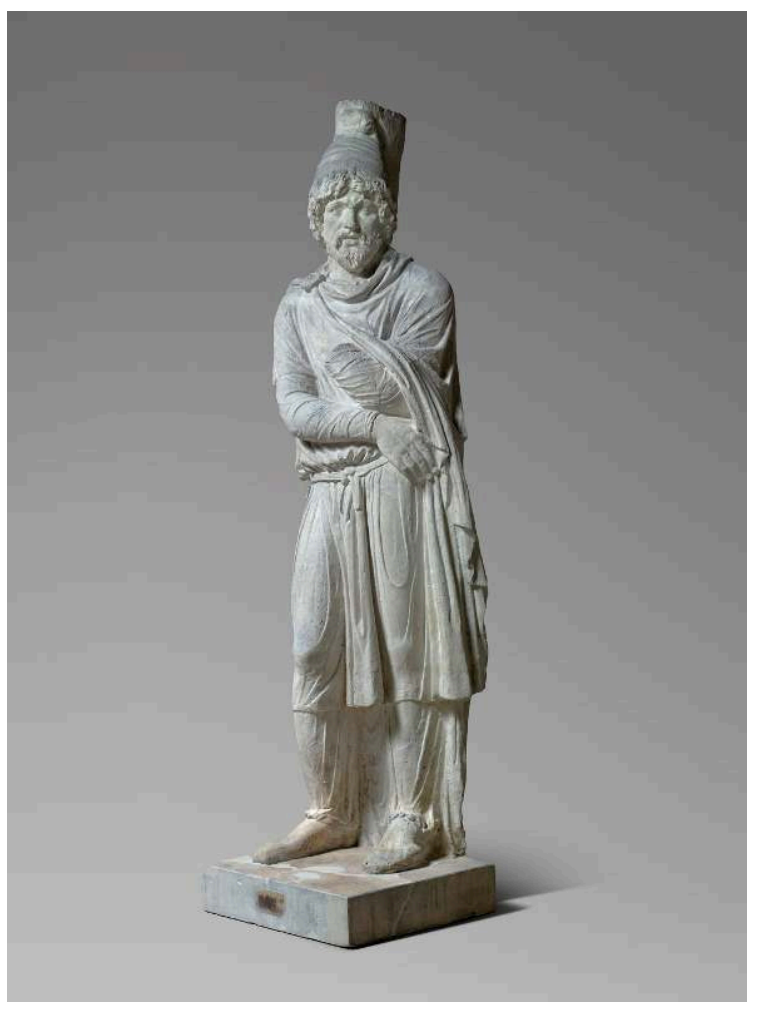

Tigrane, roi d'Arménie (généralement associé à Tiridate, roi d'Arménie, ils sont alors souvent nommés Les Esclaves Daces, Les Deux Rois esclaves, Les Prisonniers Farnèse, Les Rois parthes) tirage intégral en plâtre (moule à bon creux et à pièces) réalisé avant 1673 (h. 254 x I. 69 × p. $45 \mathrm{~cm}$ ) conservé à la gypsothèque du musée du Louvre (Gy 0208), Petite Écurie du roi à Versailles (œuvre originale conservée au Musée archéologique de Naples, Italie).

(c) Photo Hervé Lewandowski (RMN-Grand Palais). 
Figure 16

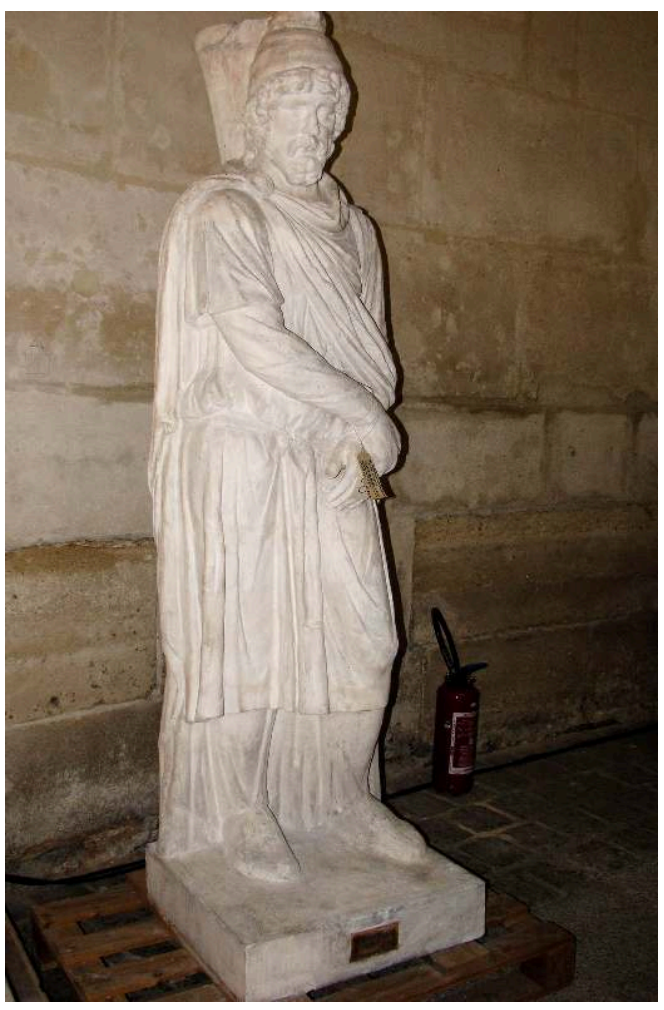

Tigrane, roi d'Arménie, tirage intégral en plâtre (moule à bon creux et à pièces) réalisé avant 1673 (h. 233 x I. 71 x p. $60 \mathrm{~cm}$ ) conservé à la gypsothèque du musée du Louvre (Gy 0206), Petite Écurie du roi à Versailles (œuvre originale conservée au Musée archéologique de Naples, Italie).

(c) Photo Musée du Louvre / AGER, Service d'étude et de documentation. 


\section{Figure 17}

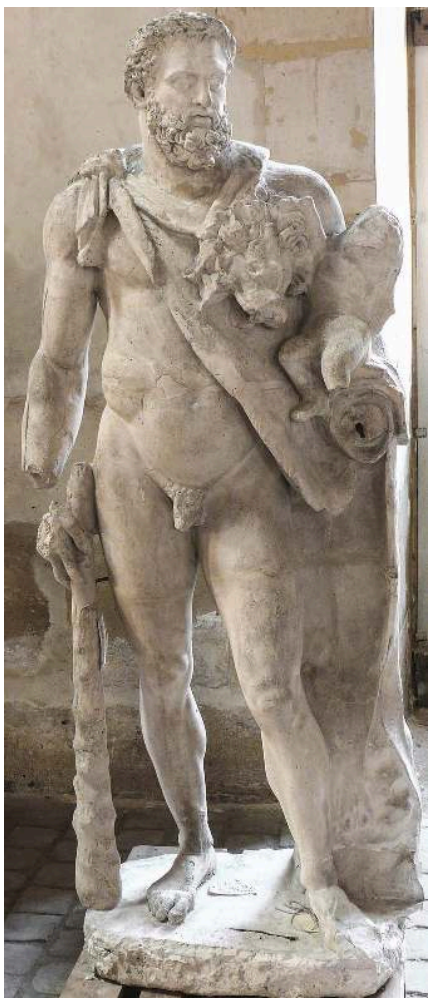

Commode en Hercule du musée du Louvre, autrement nommé Hercule portant Télèphe, HerculeCommode ou encore Hercule et Ajax, tirage intégral en plâtre (moule à bon creux et à pièces) réalisé entre 1673 et 1684 (h. 220 × I. 94 x p. 60 cm) conservé à la gypsothèque du musée du Louvre (Gy 0247), Petite Écurie du roi à Versailles (œuvre originale conservée au musée Chiaramonti, Vatican).

(c) Photo Musée du Louvre / AGER, Service d'étude et de documentation. 
Figure 18

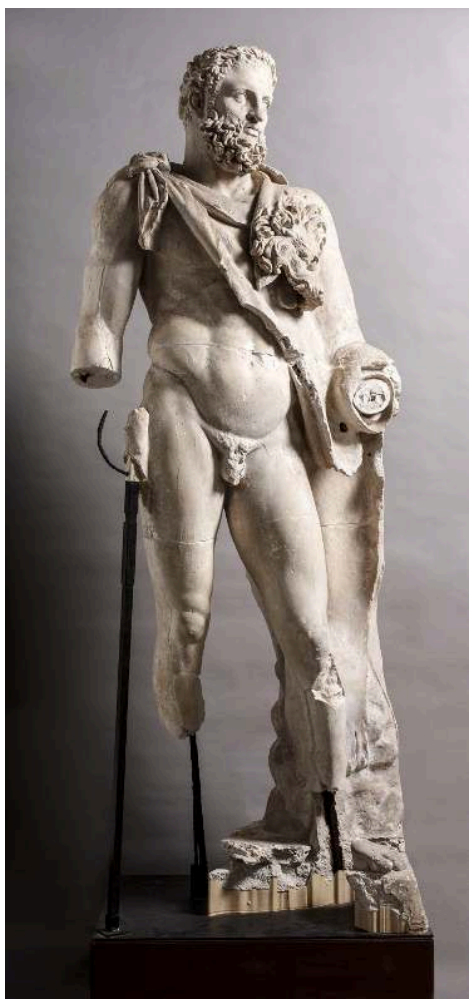

Commode en Hercule de l'Académie de France à Rome, tirage intégral en plâtre (moule à bon creux et à pièces) réalisé entre 1673 et 1684 (h. 237 × l. 62 × p. 82 cm) conservé à l'Académie de France à Rome (inv. 2015.0.225) (œuvre originale conservée au musée Chiaramonti, Vatican).

(c) Photo Giuseppe Schiavinotto / Académie de France à Rome - Villa Médicis, 2019.

Instaurées sous Louis XIV, les bonnes conditions de conservation de ces matrices, promesses de duplications conformes, sont adoptées, et auguraient ainsi la possibilité de constituer des séries/corpus fidèles à étudier mais aussi à multiplier ou diffuser. Ce «recueil» en trois dimensions, abrité aujourd'hui dans la gypsothèque du Louvre, s'enracine précisément dans ce passé lointain. En 1794, la fondation de l'Atelier de moulage du Louvre institutionnalisera ce qui était en germe.

Dans l'inventaire de Félibien, les références sont nommées; elles sont clairement identifiables et présentes pour la grande majorité dans la gypsothèque. Par la suite, les collections s'enrichissent et d'autres documents viennent compléter ce premier registre; plusieurs descriptions de salles, en particulier, publiées au cours du XVIII ${ }^{e}$ siècle, nous détaillent les œuvres in situ. Si en 1715, Nicolas Guérin ${ }^{26}$ ne mentionne encore que trente et une reproductions de sculpture et quelques morceaux d'architecture, un inventaire daté de 1793 nous en signale quant à lui déjà près de cent. Mais dans cet intervalle, d'autres ouvrages font état des collections et permettent de dresser des listes de modèles de référence assez complètes pour toute cette période. Ainsi, grâce aux publications d'Antoine-Nicolas Dezallier d'Argenville ${ }^{27}$ en 1781, et de Luc-Vincent Thiéry de Sainte-Colombe à deux reprises, en 1787, puis en $1795-1796^{28}$, les identifications de modèles sont relativement faciles à faire et nous pouvons encore les repérer dans les collections du Louvre. Mais, comme nous tentions de l'expliquer, reconnaître un modèle n'est ni donner ni prouver sa datation: celle-ci est en effet 
beaucoup plus complexe à avancer même si un pas important a été franchi depuis $2012^{29}$.

19 Une carte d'identité des plâtres anciens a été élaborée, quinze statues de nos collections sont clairement reconnues comme datant $\mathrm{du} \mathrm{XVII}^{\mathrm{e}}$; certaines présentent même, fait exceptionnel, des éléments qui nous permettent d'affirmer qu'elles ont servi de modèle à des œuvres copiées à ce moment-là [fig. 12].

Un ensemble de vingt-quatre plaques ou fragments de reliefs de la colonne Trajane de la gypsothèque du Louvre a été daté du $\mathrm{XVII}^{\mathrm{e}}$ siècle : l'une de ces plaques porte, cas rarissime, une date inscrite et gravée, « $1669 »^{30}$ [fig. 5].

21 Même si les déménagements et les conditions de conservation parfois rudes que les

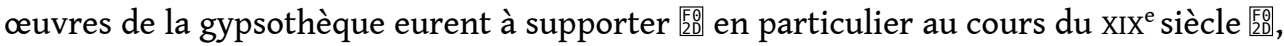
ont occasionné des fortunes bien diverses, la poursuite des travaux de recherche et de restauration viendra certainement enrichir ce groupe.

\section{Le plâtre au service de l'instruction publique}

Remise au goût du jour avec les Lumières, l'Antiquité s'impose dès le dernier quart du $\mathrm{XVII}^{\mathrm{e}}$ siècle et plus encore au XVIII , redonnant une place d'honneur aux plâtres des palais royaux et des Académies. Remarquables vecteurs de diffusion, ceux-ci sont présents, massivement cette fois, dans les écoles, les ateliers d'artistes et les cercles les plus privés. En effet, le phénomène du Grand Tour, qui se développe, la multiplication des découvertes archéologiques, les débats puis l'élaboration de théories autour du «Beau idéal » créent les conditions nécessaires à l'épanouissement d'une anticomanie européenne qui privilégie les œuvres romaines et blanches. Mais celle-ci se manifeste davantage encore, confortée et démultipliée, renforcée par les conceptions révolutionnaires désireux de promouvoir l'instruction publique à partir de 1791. L'art est alors convoqué pour jouer un rôle de premier plan dans l'instruction.

De ce courant qui prend de l'importance au cours de la dernière décennie du XVIII et marque le XIX ${ }^{e}$ siècle émergent de nombreux projets et réformes qui visent à rendre l'instruction publique accessible au plus grand nombre; le moulage est un des principaux agents de cette démocratisation de l'enseignement et les tirages, un instrument de formation.

24 Un des actes majeurs, la fondation du Muséum central des arts de la République, le 27 juillet 1793, est suivi de la suppression des Académies ${ }^{31}$. L'Académie royale, en tant qu'institution honorifique, disparait, mais l'École académique de peinture et de sculpture, avec son corps enseignant ${ }^{32}$, reste au Louvre ; les modèles d'étude demeurent donc intra-muros. L'ouvrage de Thiéry de Sainte-Colombe, rédigé en 1795-1796 ${ }^{33}$, donne un état des salles et constitue une source fondamentale quand il s'agit de repérer les tirages ou plus simplement les modèles de référence qui ont été abrités au Louvre durant cette période. Il n'est pas impossible que certains aient survécu, et soient aujourd'hui préservés sous les voûtes de Mansart. 


\section{Pour l'instruction de la nation : un atelier de moulage au Louvre et des écoles centrales en France}

Dans le sillage de ces actions, et toujours au service de l'instruction de la nation et de la diffusion de la connaissance, est fondé le 24 frimaire an III (14 décembre 1794) un atelier de moulage au Louvre ${ }^{34}$ dont la valeur initiale forte, clairement exprimée, est bien la constitution d'un répertoire de formes de qualité, blanc, à vocation pédagogique. Il est mieux compris quand, par ailleurs et peu après, par un décret du 7 ventôse an III (25 février 1795), le comité d'Instruction publique fonde les écoles centrales $^{35}$. Manifestation de la rupture avec le système éducatif précédent tel qu'il était dispensé dans les collèges de l'Ancien Régime, on y remarque en particulier dans les programmes la place importante accordée à l'enseignement du dessin, dès la première section, soit aux élèves qui ont entre 12 et 14 ans.

Pour honorer ces nouvelles idées est alors savamment étudié et choisi un corpus dans lequel les « icônes » demeurent privilégiées, même si de nouveaux modèles se profilent déjà. L'Atelier de moulage s'acquitte alors de la tâche en réalisant la première collection "publique » de tirages en plâtre ${ }^{36}$. Parmi les premiers moules exécutés et modèles diffusés, on reconnaît les grandes références antiques, celles du groupe de Castor et Pollux, de Cincinnatus, de l'Apollon du Belvédère, de l'Hermaphrodite et du Gladiateur

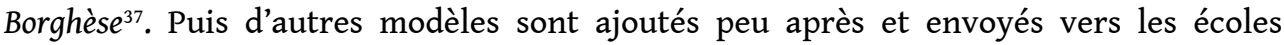
centrales. Une démarche qui s'inscrit par ailleurs sur l'idée, défendue par une partie de l'opinion, selon laquelle :

C'est par une longue habitude du vrai et du beau que nous formons notre goût. Les Romains, jadis grossiers, sont parvenus à civiliser leur nation, en transplantant chez eux ces productions de la Grèce vaincue. [...] Le véritable but des arts ne fut jamais de contenter la vanité d'un petit nombre de riches; les arts ont une fin plus utile et plus grande, c'est d'instruire une nation, de former ses mœurs, son goût, et de graver dans sa pensée des images qui lui rappellent sans cesse de hautes vertus et sa propre dignité. Ainsi, il est temps que le Peuple français apprenne à aimer et à juger les arts comme il convient à un peuple libre; qu'il prenne aussi des sentiments conformes à sa nouvelle situation ${ }^{38}$.

L'Atelier poursuit son activité, et commence la rédaction de listes manuscrites de modèles en 1805 ; les premiers catalogues de vente apparaissent beaucoup plus tard, à partir de 1864 : s'y reflète la vénération des « icônes » romaines, encore loin de faiblir.

L'École centrale des Quatre-Nations, située en face du Louvre, de l'autre côté de la Seine, dut être destinataire de plâtres comme toutes les autres écoles. Pour ce qui concerne notre sujet, cet établissement a une importance singulière ; car ces écoles riches de plâtres ne furent actives que sur une courte période, de 1796 à 1802. Dès 1803, le lieu, devenu «École royale et spéciale des beaux-arts ", héberge tout d'abord, comme nous allons le développer un musée, la Galerie d'architecture de Dufourny, et des collections en provenance du Muséum.

Mais que sont devenus les modèles de l'école centrale ? Ont-ils été conservés sur place à la fermeture et dispersés ensuite ? Il s'agit d'une enquête à ouvrir. 


\section{Du Louvre au palais des Quatre-Nations : la Galerie d'architecture de Dufourny}

Simultanément, précisément en 1798, en vertu du traité de Tolentino, un changement majeur intervient au Muséum central des arts de la République. Les salles s'ornent d'un nombre très important d'œuvres d'art en provenance d'Italie, dont les marbres des grandes collections des États pontificaux. Il s'agit principalement de statues, bustes et bas-reliefs. Les œuvres sont exposées à proximité d'un musée sur lequel nous sommes assez mal renseignés. Placé sous la responsabilité de l'architecte Léon Dufourny (1754-1818), le " musée d'Architecture ${ }^{39}$ ", assez éclectique dans sa constitution et riche de près de 1200 éléments, semble avoir été composé de la réunion de trois ensembles moulés sur l'antique. On y trouvait ainsi $\mathrm{i}^{40}$ :

$1^{\circ}$ Tous les (plâtres) ornements et détails d'architecture que Choiseul-Gouffier avait fait mouler sur les antiquités d'Athènes, dont tous les bas-reliefs qui ornent les métopes des temples de Thésée et de Minerve, chacun de 3 (pieds) 6 (pouces) sur 3 , et au nombre de quarante environ; ces plâtres faisaient partie du grand convoi d'objets d'art à ce moment aux portes de Paris.

$2^{\circ}$ Les grands chapiteaux et autres ornements, moulés à Rome sur l'antique, qui existaient à la ci-devant église de la Madeleine, au nombre d'environ 150 morceaux. $3^{\circ}$ Enfin, la collection d'ornements antiques et modernes, recueillis en Italie par le c[itoyen] Dufourny, collection qui consistait en plus de 1000 morceaux, dont plusieurs de grandes dimensions, tels que les belles frises de la villa Médicis et les façades du piédestal de la colonne Trajane, etc.

De cette énumération, nous retenons surtout qu'avec les œuvres d'art du comte MarieGabriel-Florent-Auguste de Choiseul-Gouffier (1752-1817), confisquées comme «biens des émigrés ", et distraites par décret ${ }^{41}$ des entrepôts de Marseille, l'art grec fait son entrée au Muséum [fig. 19]. Nous pouvons espérer en retrouver dans la gypsothèque du Louvre. C'est moins assuré pour les chapiteaux corinthiens de Guillaume-Martin Couture, saisis eux aussi. 


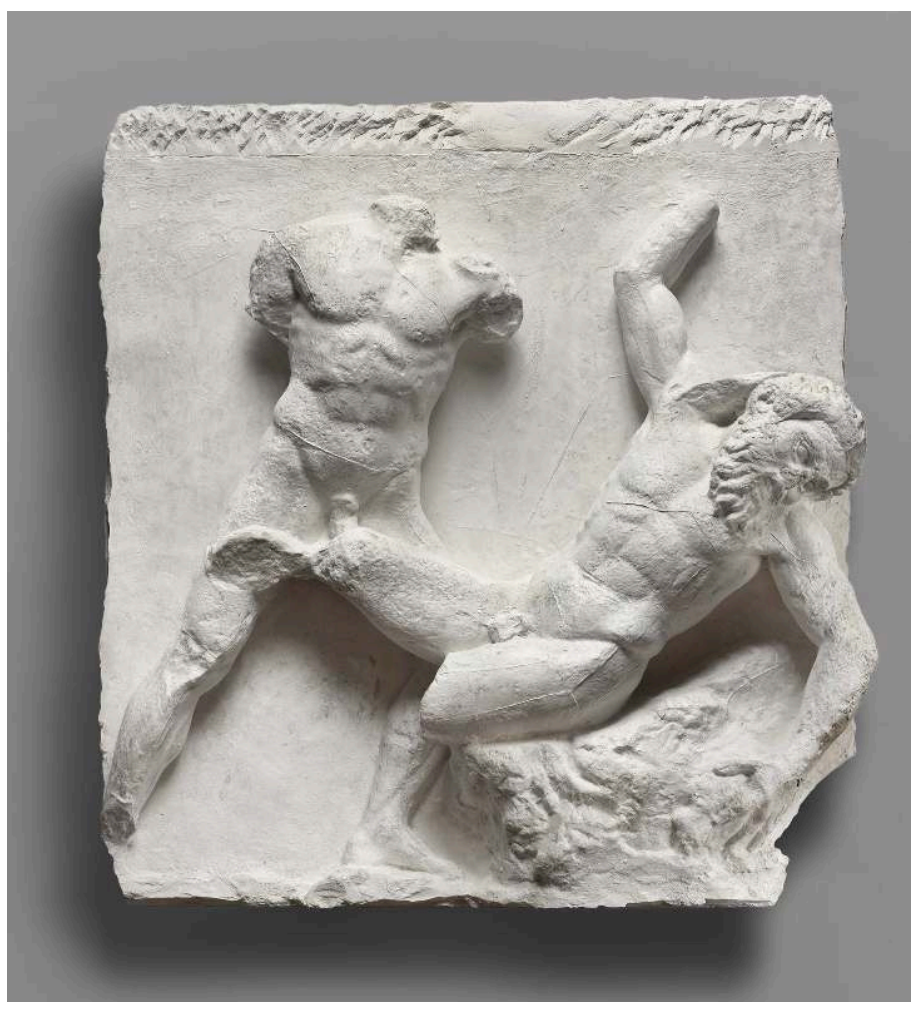

Métope de l'Héphaïsteion représentant Thésée et Scyron, autrement nommé Métope du temple de Thésée, tirage intégral en plâtre (moule à bon creux et à pièces) $(\mathrm{h} .79 \times 1.72 \times$ p. $17 \mathrm{~cm}$ ) conservé à la gypsothèque du musée du Louvre (Gy 0476), Petite Écurie du roi à Versailles.

(c) Photo Hervé Lewandowski (RMN-Grand Palais).

Rapidement, et compte tenu du contexte, ce musée d'architecture connu surtout pour la brièveté de son existence est soudainement devenu bien encombrant. Il quitte le Louvre en 1803, est recomposé rive gauche, dans les murs de ce qui avait donc été l'École centrale des Quatre-Nations. Connu alors sous le nom « Galerie d'architecture de Dufourny ", il est complété dès cette année de pièces de moulages de Dufourny en provenance d'Italie, encore dans leurs caisses, et prévues initialement pour le Louvre ${ }^{42}$, puis enrichi en 1813-1814 $4^{43}$ d'une collection dite des «modèles d'architecture ${ }^{44}$ ", des maquettes réalisées par Louis-François Cassas ${ }^{45}$, dont l'École des beaux-arts fera l'acquisition plus tard, en 1832.

Au Louvre, l'École académique de peinture et de sculpture et ses collections restées sur place en 1793, au moment de la suppression des Académies, deviennent elles-mêmes vite embarrassantes; le manque de place lié à l'arrivée des antiques d'Italie les condamne et l'École est déplacée à son tour en 1807. L'inventaire des Musées royaux dressé en 1832 témoigne en revanche du fait que les tirages des collections royales furent maintenus in situ. Les collections de l'Académie avant transfert sont alors partagées. Une partie reste au Louvre, mais ce n'est pas le cas des plâtres qui, semble-til, traversent la Seine et rejoignent la Galerie d'architecture de Dufourny au palais des Quatre-Nations. Mais le parcours des pièces n'est ni simple ni linéaire. Seul le sort de la collection de maquettes en talc ou en liège est clair : elle est toujours portée disparue en 2020! Quant aux plâtres du musée d'architecture, fondus dans la Galerie d'architecture de Dufourny, ils sont complétés des collections de l'École académique 
royale de peinture et de sculpture, et constitueront le fonds ancien de l'École des beaux-arts.

Ainsi, dans la gypsothèque du Louvre se trouve certainement un assez grand nombre de modèles qui ont traversé la Seine et le temps, dont certains éléments d'architecture du XVIII ${ }^{\mathrm{e}}$ siècle. Cependant, même si la collection est reconnue pour son ensemble d'ordres et de modèles architecturaux sans égal, l'histoire de la gypsothèque comporte encore des points obscurs, les datations étant toujours très complexes à établir.

Quoi qu'il en soit, cette nouvelle institution installée au palais des Quatre-Nations, connue sous le nom d'École royale et spéciale des beaux-arts, est enrichie si abondamment par l'arrivée de ces ensembles du Louvre qu'elle s'y trouve vite à l'étroit. Peu après, l'application du traité de Vienne de 1815 entraîna la restitution des œuvres, en grande partie propriété des États pontificaux. Le Muséum fut soudainement vidé des chefs-d'œuvre de l'art antique tant acclamés à Paris en 1798 et l'on aurait pu imaginer que les plâtres, que précisément, le traité de Tolentino avait chassés en 1803, auraient fait leur retour. Cela eut été facile, et pourtant, il n'en fut rien! Conformément aux valeurs du Comité d'instruction publique, une distinction claire fut établie: un lieu serait dévolu spécifiquement à la pédagogie, aux beaux-arts, en un mot aux praticiens, et un autre, au public, aux amateurs. Une ordonnance royale du 24 avril 1816, en remédiant à l'exiguïté du palais des Quatre-Nations, consacra cette volonté et dota l'École royale et spéciale des beaux-arts d'un lieu plus spacieux.

Une nouvelle page de l'histoire s'ouvrait alors à quelques pas de là, celle de la création de la Nouvelle École royale et spéciale des beaux-arts, tandis qu'au Muséum de nouvelles initiatives voyaient le jour.

\section{NOTES}

1. DELACROIX Eugène, CEuvres littéraires, vol. 1, Études esthétiques, 1829-1863, Paris, G. Crès \& Cie, coll. «Bibliothèque dionysienne», 1923 [disponible en ligne], http://classiques.uqac.ca/ classiques/delacroix_eugene/etudes_esthetiques/etudes_esthetiques.html $[$ lien valide en novembre 2020].

2. MAZARS Pierre, Le Figaro, 28 mars 1969.

3. Le terme « moulage " prête à confusion du fait d'être souvent employé indifféremment pour la technique et pour l'objet, aussi préférons-nous employer les termes «tirage ", «jet " ou «forme » pour désigner l'objet en plâtre obtenu par la technique du moulage. Pour évoquer cette dernière, nous employons volontiers les verbes "mouler ", "jeter ", «former ", et pour les moules eux-mêmes les mots « creux » ou « matrice ».

4. Emblématique, la majestueuse statue de Melpomène fut décapitée en novembre 1968 par la chute d'une corniche, en raison de la vétusté des lieux. Elle n'en demeure pas moins symboliquement l'image de la fin d'un système. GARCIA Anne-Marie, « La collection d'antiques à l'École des beaux-arts, de 1870 à 1970 », in LE BRETON Élisabeth \& MARTINEZ Jean-Luc (dir.), Une Antiquité moderne, catalogue d'exposition (Académie de France à Rome, villa Médicis, 7 novembre 2019-1 ${ }^{\mathrm{er}}$ mars 2020), Rome / Paris, Villa Médicis, Académie de France à Rome / Louvre, p. 188-193. 
5. Les collections de l'École des beaux-arts de Paris, aujourd'hui, École nationale supérieure des beaux-arts de Paris (ENSBA), ont été évacuées entre le 17 août et le 5 novembre 1970. Celles de l'université de la Sorbonne dépendant alors de l'UER d'Art et d'Archéologie de l'université Paris-I, installée à l'étage de l'Institut d'art et d'archéologie de la rue Michelet (Paris), ont été évacuées entre le 17 et le 26 juillet 1973. Voir MARTINEZ Jean-Luc, «La gypsothèque du musée du Louvre à Versailles", Académie des inscriptions et belles-lettres. Comptes rendus des séances, séance du 9 octobre, 2009, p.1127-1152; PINATEL Christiane, «Valeurs et perceptions de plâtres artistiques: origines oubliées de moulages dans la collection de Versailles », in BARTHE Georges (dir.), Le Plâtre. L'art et la matière, actes du colloque organisé par le Groupe de recherche sur le plâtre dans l'art (Cergy-Pontoise, octobre 2000), Paris, Créaphis, 2001, p.162-171; MARTINEZ Jean-Luc, « La collection de moulages : un musée pédagogique », in TEXIER Simon (dir.), L'Institut d'art et d'archéologie, Paris, 1932, Paris, Picard, 2005, p. 93-104.

6. La décision, prise par Jean Châtelain, directeur des Musées de France de 1962 à 1974, fut mise en application, jusqu'en 1978. Voir BESQUES Simone, "Le musée des Monuments antiques à Versailles », Comptes rendus de l'Académie des inscriptions et belles-lettres, 1977, p. 240-243.

7. La collection est placée sous la responsabilité du musée du Louvre par un arrêté d'affectation du ministère de la Culture et de la Communication, signé par Catherine Tasca et daté de décembre 2001, au profit du département des Antiquités grecques, étrusques et romaines du musée du Louvre.

8. Les creux dont ils sont issus ne sont pas conservés dans la collection.

9. FONTAINE André, L'Art dans l'ancienne France. Les collections de l'Académie royale de peinture et de sculpture, Paris, Henri Laurens, 1910 ; FRÉART de CHANTELOU Paul, Journal du voyage du cavalier Bernin en France, Paris, Gazette des beaux-arts, 1885 [rééd. Aix-en-Provence, Pandora, coll. « Art et architecture », 1981].

10. Les fouilles archéologiques menées en 1954 dans un complexe de bains situé à Baia ont mis au jour pas moins de 400 fragments de sculptures de plâtre. Il a été mis en évidence qu'il s'agissait de fragments moulés de célèbres statues grecques en bronze des $\mathrm{V}^{\mathrm{e}}$ ou IV $\mathrm{IV}^{\mathrm{e}}$ siècles avant J.-C. Le site de Baïes connut une période florissante au $\mathrm{I}^{\mathrm{er}}$ siècle avant J.-C. Voir LANDWEHR Christa, Die antiken Gipsabgüsse aus Baiae. Griechische Bronzestatuen in Abgüssen römischer Zeit. Berlin, Mann, 1985 : pour le contexte de découverte, p. 1-7; pour le procédé de création de moulages antiques, p. 12-25. Voir également KADERKA Karolina, «L'appropriation de la Grèce antique par les Romains à travers la sculpture», in LE BRETON Élisabeth \& MARTINEZ Jean-Luc (dir.), Une Antiquité moderne, p. 21-24.

11. LE BRETON Élisabeth, « Pour une Antiquité moderne, entre esthétique et idéologie, $d u X I_{I}{ }^{e}$ au $\mathrm{XX}^{\mathrm{e}}$ siècle », in LE BRETON Élisabeth \& MARTINEZ Jean-Luc (dir.), Une Antiquité moderne, p. 13-17.

12. BARBET DE JOUY Henry, Étude sur les fontes du Primatice, Paris, Vve J. Renouard, 1860, p. 5, 9 et 11 .

13. Les creux furent vendus à la reine Marie de Hongrie, gouvernante des Flandres, sœur de Charles Quint. Elle les acheta pour des jets qui allaient orner son palais à Binche, au sud de Bruxelles.

14. LE BRETON Élisabeth, «Les «familles de Niobé à la villa Médicis », in LE BRETON Élisabeth \& MARTINEZ Jean-Luc (dir.), Une Antiquité moderne, p. 88-95.

15. ROTHKOPF Scott (dir.), Jeff Koons. La rétrospective, catalogue d'exposition (Centre Pompidou, Paris, 26 novembre 2014-27 avril 2015), Paris, Éditions du Centre Pompidou, 2014.

16. Nous sommes renseignés par une estampille métallique incrustée et marquée "Leopoldo Malpiéri formatore Roma ».

17. Le surmoulage est l'opération qui consiste à mouler ou faire une prise d'empreinte sur un précédent tirage. Par souci de clarté, nous préférons appeler le résultat de cette technique surtirage.

18. BOUCHITTÉ Louis Firmin Hervé, Le Poussin, sa vie et son œuvre, Paris, Didier, 1858, p. 74. 
19. Trois pièces en mars 1692, une pièce en novembre 1693 et seize le 26 avril 1710 ( Inventaire des sculptures moulées en plastre sur l'Antique données par le Roy », manuscrit conservé à la bibliothèque de l'ENSBA, Paris, ms 35).

20. La « Grande Commande » date de 1674 et s'étend sur une vingtaine d'années. Elle est nommée ainsi par opposition à une petite commande de huit statues faite en 1664 . Elles ont été passées pour la réalisation du programme iconographique à développer dans le parc du château à Versailles.

21. Inventaire rédigé par Félibien, du 10 novembre 1692 (AN, $\left.\mathrm{O}^{1^{*}} 1977^{\mathrm{A}}, 1-68\right)$. Voir LE BRETON Élisabeth, «Le premier inventaire au palais du Louvre par Félibien en 1692, du XVII ${ }^{\mathrm{e}}$ au $\mathrm{XX}^{\mathrm{e}}$ siècle », in LE BRETON Élisabeth \& MARTINEZ Jean-Luc (dir.), Une Antiquité moderne, p. 96-99.

22. Voir ci-dessus note 3.

23. BRESC Geneviève, «Le moulage de statues antiques à l'Académie de France à Rome sous Colbert et Louvois ", in LE BRETON Élisabeth \& MARTINEZ Jean-Luc (dir.), Une Antiquité moderne, p. 100-103.

24. Excepté de novembre 1852 à mars 1854, lorsque l'atelier est déplacé 48 rue Mazarine, et à partir de 1928 quand, devenu "Atelier de moulages des Musées nationaux», il quitte définitivement le Louvre pour être installé dans l'aile de Passy du Trocadéro. En 1990, l'institution est classée comme Établissement public à caractère industriel et commercial (Épic), puis déplacée à la Plaine-Saint-Denis en 1994.

25. RIONNET Florence, L'Atelier de moulage du Louvre. 1794-1928, Paris, Réunion des musées nationaux, coll. « Notes et documents des musées de France», 1996 ; RIONNET Florence, «Un instrument de propagande artistique : l'atelier de moulage du Louvre ». Revue de l'art, 1994, $\mathrm{n}^{\circ} 104, \quad$ p. 49-50 [disponible en ligne], https://www.persee.fr/doc/ rvart_0035-1326_1994_num_104_1_348127 [lien valide en novembre 2020].

26. GUÉRIN Nicolas, Description de l'Académie royale des arts de peinture et de sculpture, par feu M. Guérin, Paris, Jacques Collombat, 1715.

27. DEZALLIER d'ARGENVILLE Antoine-Nicolas, Description sommaire des ouvrages de peinture, sculpture et gravure exposés dans les salles de l'Académie royale, Paris, De Bure père, 1781.

28. THIÉRY de SAINTE-COLOMBE Luc-Vincent, Guide des amateurs et des étrangers voyageurs à Paris, ou Description raisonnée de cette ville, de sa banlieue, et de tout ce qu'elles contiennent de remarquable, Paris, Hardouin et Gattey, 1787, t. 1 ; THIÉRY de SAINTE-COLOMBE Luc-Vincent, Paris tel qu'il étoit avant la Révolution, ou Description raisonnée de cette ville, de sa banlieue et de tout ce qu'elles contenoient de remarquable pour servir de guide aux amateurs et voyageurs français et étrangers, Paris, Delaplace, 1795-1796, t. 1.

29. LE BRETON Élisabeth, "Le moulage. Pratiques historiques et regards contemporains ", communication aux journées d'études des 14-15 novembre 2012 (Cité de l'architecture et du patrimoine, Paris); LE BRETON Élisabeth, «Les tirages en plâtre du XVII ${ }^{\mathrm{e}}$ siècle dans la gypsothèque du musée du Louvre. Apport des restaurations récentes ", Monuments et mémoires de la Fondation Eugène-Piot, Paris, Académie des inscriptions et belles-lettres, coll. « Monuments et mémoires de la Fondation Eugène-Piot ", t.92, 2013, p. 67-92 [disponible en ligne] https:// www.persee.fr/doc/piot_1148-6023_2013_num_92_1_2123 [lien valide en novembre 2020]; LE BRETON Élisabeth, «Gypsothèque du musée du Louvre. Les apports de la restauration à la datation des tirages en plâtre anciens ", In Situ. Revue des patrimoines [en ligne], $n^{\circ} 28$, "Le moulage. Pratiques historiques et regards contemporains ", 2016, http:// journals.openedition.org/insitu/12581 [lien valide en novembre 2020].

30. DÉLIVRÉ Jean, «Une affaire d'État: le moulage de la colonne Trajane au XVII siècle», in LE BRETON Élisabeth \& MARTINEZ Jean-Luc (dir.), Une Antiquité moderne, p. 104-107.

31. Décret daté du 8 août 1793.

32. MÜNTZ Eugène, "Le musée de l'École des beaux-arts, I ", Gazette des beaux-arts, $1^{\mathrm{er}}$ janvier 1890, p. 273-289. 
33. Voir note 22.

34. Ce premier atelier de moulage sera connu plus tard sous le nom «Atelier de moulage du Louvre », et aujourd'hui sous le nom « Ateliers d'art de la Réunion des musées nationaux - GrandPalais ».

35. En 1802, quatre-vingt quinze villes en France, généralement des chefs-lieux de département, sont dotées d'une école centrale, se substituant aux collèges des facultés des Arts d'Ancien Régime, équivalant plus ou moins aux collèges actuels. À Paris, trois sont créées. dont l'une est établie en 1796 dans l'ancien collège des Quatre-Nations : il s'agit de l'École centrale des QuatreNations, qui fut supprimée, comme toutes les autres, le 11 floréal an X ( $1^{\mathrm{er}}$ mai 1802).

36. RIONNET Florence, L'Atelier de moulage du Louvre, p. 7.

37. Les modèles des trois premières œuvres font toujours partie des collections de la gypsothèque mais ils sont encore mal datés.

38. « Pétition adressée au Directoire le 12 vendémiaire an IV (30 octobre 1796), par trente-sept artistes, pour soutenir la politique des saisies d'œuvres d'art en Italie », reproduite dans LAPORTE Marie-Alix, «Les saisies d'œuvres d'art pendant le Triennio révolutionnaire : réactions française et italienne ", mémoire de master I sous la direction de Gilles Bertrand soutenu à l'université Pierre-Mendès-France (Grenoble), 2008, annexe 14, p. 109-112.

39. SZAMBIEN Werner, «Le musée d'architecture (1776-1836), un projet inachevé », ms., Paris, I.E.R.A.V-École d'architecture de Paris-Belleville, 1984, p. 34 ; SZAMBIEN Werner, Le Musée d'architecture, Paris, Picard, 1988, p. 31. Un premier projet conçu autour de la cour du Sphinx par les architectes Jacques-Guillaume Legrand et Jacques Molinos date de 1790. Il fut suivi de deux autres, en 1792 et 1795 .

40. SZAMBIEN Werner, Le Musée d'architecture, p. 278.

41. Décret du 10 octobre 1792. Liste Archives des musées nationaux, AN, Z4, 1797, dossier 26 oct. (date de bas de page «1797, 22 oct. ») ; MARCADÉ Jean \& PINATEL Christiane, « Les avatars de la plaque des Ergastines du Louvre au XIX siècle », in BERGER Ernst (dir.), Parthenon-Kongress Basel, 4. bis 8. April 1982. Referate und Berichte, Mayence, Philipp von Zabern, 1984, p. 338 et 455 note 9.

42. PINATEL Christiane, «Origines de la collection des moulages d'antiques de l'École nationale des beaux-arts de Paris, aujourd'hui à Versailles", in LAURENS Annie-France \& POMIAN Krzysztof (dir.), L'Anticomanie. La collection d'antiquités aux XVIII et XIX siècles, Paris, Éditions de l'EHESS, 1992, p. 314.

43. MÜNTZ Eugène, «Le musée de l'École des beaux-arts, I », p. 279.

44. LANEYRIE-DAGEN Nadeije, "Louis Peisse et "le musée des modèles" à l'École des beaux-arts ", Bulletin de la Société de l'histoire de l'art français, année 1985 [1987]. Rapport au ministre de l'Intérieur, p. 230. Les modèles ont été réalisés pour la majorité en talc et quelques-uns en liège. 45. Louis-François Cassas (1756-1827), protégé du comte de Choiseul-Gouffier, est l'auteur de nombreux dessins de sites archéologiques d'Italie et du Moyen-Orient.

\section{RÉSUMÉS}

C'est sur les ruines d'un vaste ensemble de plâtres de modèles antiques désacralisés à partir de 1968 que se dresse, depuis 2001, la gypsothèque du musée du Louvre. Près de vingt ans de restaurations et de recherches permettent aujourd'hui de raviver la mémoire d'une partie de ces quelque 5500 œuvres abritées sous les hautes voûtes de la Petite Écurie du roi à Versailles. 
En effet, la découverte de "cartes d'identités" spécifiques autorise à brosser une fresque chronologique de l'appropriation des modèles antiques à Paris $\mathrm{du} \mathrm{XVI}^{\mathrm{e}}$ au $\mathrm{Xx}^{\mathrm{e}}$ siècle et offre ainsi une meilleure compréhension des desseins qui ont présidé à ces choix d'œuvres.

Les premiers "plastres", tous romains, substituts comparables aux marbres que l'on redécouvre à la Renaissance mais qu'il est interdit de sortir des États pontificaux, sont présents dans les collections royales, en grand nombre dans la salle des Antiques du roi, puis à partir de 1666, progressivement, dans celles de l'Académie royale de peinture et de sculpture voisine. À la fin du $\mathrm{XVIII}^{\mathrm{e}}$ siècle, un renversement de situation s'opère ; les plâtres sont retirés des lieux privés et clos auxquels ils étaient réservés pour être, désormais appelés à jouer un rôle majeur dans l'Instruction publique. Dès 1791, les modèles sont diffusés et en 1794, un atelier de moulage est fondé au Louvre. La démocratisation de l'art est au cœur des initiatives révolutionnaires et conduit à transférer les collections du Louvre sur la rive gauche de la Seine, pour un autre destin, dans l'«École royale et spéciale des beaux-arts », porteur, à partir de 1816, d'un dessein plus ambitieux encore avec la « Nouvelle École royale et spéciale des beaux-arts » à Paris.

It's on the ruins of a vast collection of plaster casts of classical antiquity sculpture demystified since 1968 that is standing, since 2001, the gypsothèque (mouldings library) of the Louvre Museum. Nearly two decades of restoration and research made it possible today to rekindle the memory of some part of these 5,500 works sheltered under the high vaulted ceilings of the Petite Écurie du roi, the King's Small Stables at Versailles.

Indeed, the finding of specific "identity cards" enabled the creation of a historical timeline of the appropriation of these models from the Antiquity in Paris from the 16th to the 20th century and thereby offers a better understanding of the intent behind those selections of works.

The first "plastres", all Roman, substitutes similar to the marbles rediscovered during the Renaissance period but that were not allowed to be removed from the Papal States, were present in the royal collections. They were in great numbers in the King's Room of Antiques, then, from 1666, they were gradually present in the rooms of the "Académie royale de peinture et de sculpture" ("Royal Academy of painting and sculpture") next-door. A the end of the 18th century, a complete change in the situation occurred; plasters were removed from the private and enclosed places where they were kept, to be henceforth, called upon to play a major role in the Public education. From 1791 onwards, the models circulated and in 1794, a moulding workshop was founded in the Louvre. The democratization of art was at the core of revolutionary initiatives and led to the transfer of the Louvre's collections to the left bank of the Seine, for a different fate, in the "École royale et spéciale des beaux-arts" (the "Royal and special school of fine arts"), that will undertaking a much more ambitious project, from 1816 onwards, in the "Nouvelle École royale et spéciale des beaux-arts" ("New Royal and Special School of Fine Arts") in Paris.

\section{INDEX}

Keywords : Royal Academy of Painting and Sculpture, French Academy in Rome, Central Museum for the Arts of the French Republic, public education, central schools, Dufourny (Léon), Royal and Special School of Fine Arts, New Royal and Special School of Fine Arts, treaty of Tolentino, treaty of Vienna, plaster, moulding, Moulding Library of the Louvre Museum

Mots-clés : Académie royale de peinture et de sculpture, Académie de France à Rome, Muséum central des arts de la République, instruction publique, écoles centrales, Dufourny (Léon), École royale et spéciale des beaux-arts, Nouvelle École royale et spéciale des beaux-arts, traité de Tolentino, traité de Vienne, plâtre, moulage, gypsothèque du musée du Louvre 
AUTEUR

ÉLISABETH LE BRETON

Conservatrice au département des Antiquités grecques, étrusques et romaines du Musée du Louvre

elisabeth.lebreton@louvre.fr 